\title{
Use of Remotely Sensed Data to Enhance Estimation of Aboveground Biomass for the Dry Afromontane Forest in South-Central Ethiopia
}

\author{
Habitamu Taddese ${ }^{1,2, *(\mathbb{D})}$, Zerihun Asrat ${ }^{2,3}{ }^{\mathbb{D}}$, Ingunn Burud ${ }^{1}$, Terje Gobakken ${ }^{3}{ }^{(\mathbb{D}}$, \\ Hans Ole Ørka ${ }^{3}{ }^{D}$, Øystein B. Dick ${ }^{1}$ and Erik Næsset ${ }^{3}$ \\ 1 Faculty of Science and Technology, Norwegian University of Life Sciences, P.O. Box 5003, 1432 Ås, Norway; \\ ingunn.burud@nmbu.no (I.B.); oystein.dick@nmbu.no (Ø.B.D.) \\ 2 Wondo Genet College of Forestry and Natural Resources, Hawassa University, P.O. Box 128, \\ Shashemene 3870006, Ethiopia; zerihun.asrat.kutie@nmbu.no \\ 3 Faculty Environmental Sciences and Natural Resource Management, Norwegian University of Life Sciences, \\ P.O. Box 5003, 1432 Ås, Norway; terje.gobakken@nmbu.no (T.G.); hansole.orka@nmbu.no (H.O.Ø.); \\ erik.naesset@nmbu.no (E.N.) \\ * Correspondence: habitamu.taddese.berie@nmbu.no; Tel.: +47-4671-8534
}

Received: 31 July 2020; Accepted: 11 October 2020; Published: 13 October 2020

\begin{abstract}
Periodic assessment of forest aboveground biomass (AGB) is essential to regulate the impacts of the changing climate. However, AGB estimation using field-based sample survey (FBSS) has limited precision due to cost and accessibility constraints. Fortunately, remote sensing technologies assist to improve AGB estimation precisions. Thus, this study assessed the role of remotely sensed (RS) data in improving the precision of AGB estimation in an Afromontane forest in south-central Ethiopia. The research objectives were to identify RS variables that are useful for estimating AGB and evaluate the extent of improvement in the precision of the remote sensing-assisted AGB estimates beyond the precision of a pure FBSS. Reference AGB data for model calibration and estimation were collected from 111 systematically distributed circular sample plots (SPs) of $1000 \mathrm{~m}^{2}$ area. Independent variables were derived from Landsat-8, Sentinel-2 and PlanetScope images acquired in January 2019. The area-weighted mean and standard deviation of the spectral reflectance, spectral index and texture (only for PlanetScope) variables were extracted for each SP. A maximum of two independent variables from each image type was fitted to a generalized linear model for AGB estimation using model-assisted estimators. The results of this study revealed that the Landsat- 8 model with the predictor variable of shortwave infrared band reflectance and the PlanetScope model with the predictor variable of green band reflectance had estimation efficiency of 1.40 and 1.37, respectively. Similarly, the Sentinel-2 model, which had predictor variables of shortwave infrared reflectance and standard deviation of green leaf index, improved AGB estimation with the relative efficiency of 1.68. Utilizing freely available Sentinel-2 data seems to enhance the AGB estimation efficiency and reduce cost and extensive fieldwork in inaccessible areas.
\end{abstract}

Keywords: aboveground biomass; Sentinel-2; generalized linear model; model-assisted estimation; relative efficiency

\section{Introduction}

Forests are paramount in regulating the global environment, mainly through sequestering carbon [1]. They are particularly important these days to combat the changing climate, which affects people's lives in many aspects. Due to the multiple significance of forest resources, information about the resource base, its spatial distribution and spatio-temporal changes have become a global 
concern. The information is a basis to make decisions when planning and assessing impacts regarding mitigation and adaptation to global climate change [2-4]. Following a series of international dialogues, the conference of the parties to the United Nations Framework Convention on Climate Change (UNFCCC) has passed several decisions to combat the impacts of climate change through sequestering carbon in the living biomass, which mainly includes forests. Incentivizing the REDD+ (Reducing Emission from Deforestation and Forest Degradation, Sustainable Forest Management and Conservation) programs was one of the main issues in the Paris agreement in 2015 [4]. All these programs, initiatives and treaties require information about the resource stock and trends of changes over time.

Many forest types, which the dry Afromontane forest type is one of them, contribute to the REDD+ programs through storing carbon for mitigating the impacts of climate change. The dry Afromontane forests in Ethiopia are attributed to areas with an altitude range from 1500 to $3400 \mathrm{~m}$ above sea level; mean annual temperature of $14-25^{\circ} \mathrm{C}$; and mean annual precipitation of $400-1700 \mathrm{~mm}$ [5]. These forests are of great ecological and economic importance [6,7]. They contribute to the national and international initiatives towards biodiversity conservation, soil erosion control and the mitigation of the global climate change [6]. Although these forests are important forest types in Ethiopia and have various benefits [8], they are under pressure from the local community for expansion of agriculture, settlement and fuelwood collection $[7,9]$.

Among the forest variables, aboveground biomass (AGB) estimation is of great importance due to its multiple uses. AGB of trees is the weight of all living materials of trees above the soil surface including the stem, stump, branches, bark, seeds and leaves. A change in AGB stock can be used to monitor forest dynamics. AGB estimates, which can be converted to carbon stock estimates, are required in forest management, particularly in the implementation of the REDD+ programs that are underway in Ethiopia. Despite growing requirements for a precise estimation and timely reporting, the current tradition of measurement, monitoring and change estimation for forest resources in Ethiopia relies mainly on field-based sample surveys (FBSSs). These methods are not suitable for biomass monitoring in large areas. The FBSS methods are constrained by high costs, logistical challenges and limited field access [10]. As a result, many of the national forest inventory programs in developing countries including Ethiopia are dependent on field inventories conducted with relatively small sample sizes and thus, have high uncertainties in the estimates [11]. Studies about uncertainties of emission reduction in Ethiopia indicated that the estimates based on FBSSs with small sample size are not sufficiently precise to support decision-making [12]. The sources of uncertainties for biomass estimation using remotely sensed (RS) data can be tree measurement, allometric models or RS-based model predictions. Therefore, it is important to look for alternative approaches that can reduce costs and contribute to improving the precision of estimates from pure FBSSs.

In recent years, RS data and associated estimation techniques have become viable options to support quantification of resource stocks cost-effectively in areas inaccessible for FBSS [13-15]. Previous research has shown that RS data can help reducing FBSS efforts without loss of precision of estimates [16]. Following the improvements in RS data and technologies, there are many sources of useful satellite RS data for estimation of forest variables including AGB. Landsat and Sentinel are examples of such satellite programs, which provide freely available data $[17,18]$. Images of Landsat-8 (L8) and Sentinel-2 (S2) are useful for AGB estimation in various forest ecosystems [19-23]. However, data with higher spatial resolution are often considered better [24,25]. PlanetScope (PS) images are among potentially applicable commercial satellite RS data, which have $3 \mathrm{~m}$ spatial resolution and been acquired daily. These image characteristics make the PS data suitable for REDD+ MRV (measurement, reporting and verification) systems [25]. Compared to the L8 and S2 images, fewer studies have been carried out on biomass estimation using the PS images [26].

Various studies used either spectral band (SB) reflectance, spectral indices (SIs) or texture variables solely or in combination for AGB modelling. For example, a study by [27] on AGB estimation using Landsat TM data in the Brazilian Amazon indicated that a combination of SB and texture variables 
improved AGB estimation. The study showed the importance of texture information particularly in primary forests, which have complex canopy structures. The most commonly used SBs that correlate strongly with AGB, particularly in forests with simple stand structure, are the visible, near-infrared and shortwave infrared bands (e.g., $[27,28]$ ).

Existing scientific works found that some types of SIs contribute greatly to AGB estimation in different forest types. A study of AGB estimation using Landsat images in Northwestern Turkey revealed that SIs were better in estimating AGB in that forest type as compared to SB reflectance [29]. However, the sensitivity of SIs to biomass vary between environments and forest types [30-33]. According to the research findings by [30] in India, a significant correlation was observed between AGB and simple ratio (SR), difference vegetation index (DVI), normalized difference vegetation index (NDVI), soil adjusted vegetation index (SAVI) and modified soil adjusted vegetation index (MSAVI). Gizachew et al. [19] found that NDVI, enhance vegetation index (EVI), SAVI, MSAVI, and normalized difference moisture index (NDMI) had significant correlations with total AGB in the Miombo woodlands of Tanzania. Furthermore, atmospherically resistant vegetation index (ARVI) of L8 imagery was used for AGB estimation in Mount Tai, China [22]. A similar study in southern Portugal indicated that SIs are useful as predictors of AGB [34]. Imran et al. [35] in their study in Pakistan found that red-edge normalized difference vegetation index (RENDVI) had greater correlation with AGB than the individual SBs. Together with other SIs mentioned above, the red-edge simple ratio (SRRE) index was used for estimating AGB of mangrove forest in the Philippines [26]. Motohka et al. [36] studied the normalized difference green index (NDGI) as a good phenological indicator of various ecosystems in Japan. According to the study by [37], data collected using unmanned aerial vehicles for monitoring the post-fire recovery of pine forests in the Mediterranean areas indicated excessive green index (ExGI) as a useful variable for estimating diameter at breast height (DBH), which is a default predictor of AGB allometry. In another study, ExGI was used for discriminating vegetation types in the USA and Canada [38]. Furthermore, SIs that are indicators of leaf greenness and used in different applications including crop monitoring and discriminating vegetation types, like the green leaf index (GLI) and vegetation index (VI), were included in the current list of potential predictor variables to test if they relate to AGB. See Table 2 for detailed descriptions of the SIs explored in this study.

The other group of potentially useful variables for AGB estimation are the texture data derived from the high-resolution PS images. These variables describe the role of pixel resolution in identifying spatial variations of image values. The texture information of L8 and S2 images were not used due to the coarser resolution of these images as compared to the PS images. Several studies indicated that image texture variables could improve AGB estimation, especially in dense tropical forests [22,27,39]. The most common method of calculating image texture variables is the grey level co-occurrence matrix (GLCM). Table 3 shows how the GLCM variables were calculated.

Some studies (e.g., $[16,19,40]$ ) evaluated the use of RS data for biomass estimation in small study areas in the region of east Africa. However, to the best of our knowledge, except some efforts related to the use of Landsat images for land cover classification and mapping, data from the mentioned satellite missions subject to analysis in the current study have never been used to assess AGB of the dry Afromontane forests in Ethiopia.

Because there is little current experience with what types of variables extracted from the satellite systems in question that would be useful for AGB modelling in this forest type, the first objective of this study was to explore what kind of variables extracted from the different satellite programs might be useful for AGB modelling in the dry Afromontane forest. The second objective was to evaluate to what extent such RS data could help improving the precision of AGB estimates beyond the precision of a pure FBSS in these forests. 


\section{Materials and Methods}

\subsection{Description of the Study Area}

The study was conducted in the Degaga-Gambo forest in south-central Ethiopia. It belongs to a state-owned enterprise, Oromia Forest and Wildlife. The study area is located on the eastern escarpment of the central rift valley of Ethiopia, in the Horn of Africa (Figure 1). It extends geographically from $38^{\circ} 45^{\prime}$ to $38^{\circ} 56^{\prime} \mathrm{E}$ longitude and from $7^{\circ} 13^{\prime}$ to $7^{\circ} 33^{\prime} \mathrm{N}$ latitude. The forest has an area of 14,176 ha. The altitude of the study area ranges from 2100 to $2730 \mathrm{~m}$ above sea level. The study area has a bimodal rainfall distribution. The main rainy season is from July to September while the short rainy season is from March to May [41]. The mean annual precipitation and temperature in the area are $1245 \mathrm{~mm}$ and $14.9{ }^{\circ} \mathrm{C}$, respectively.

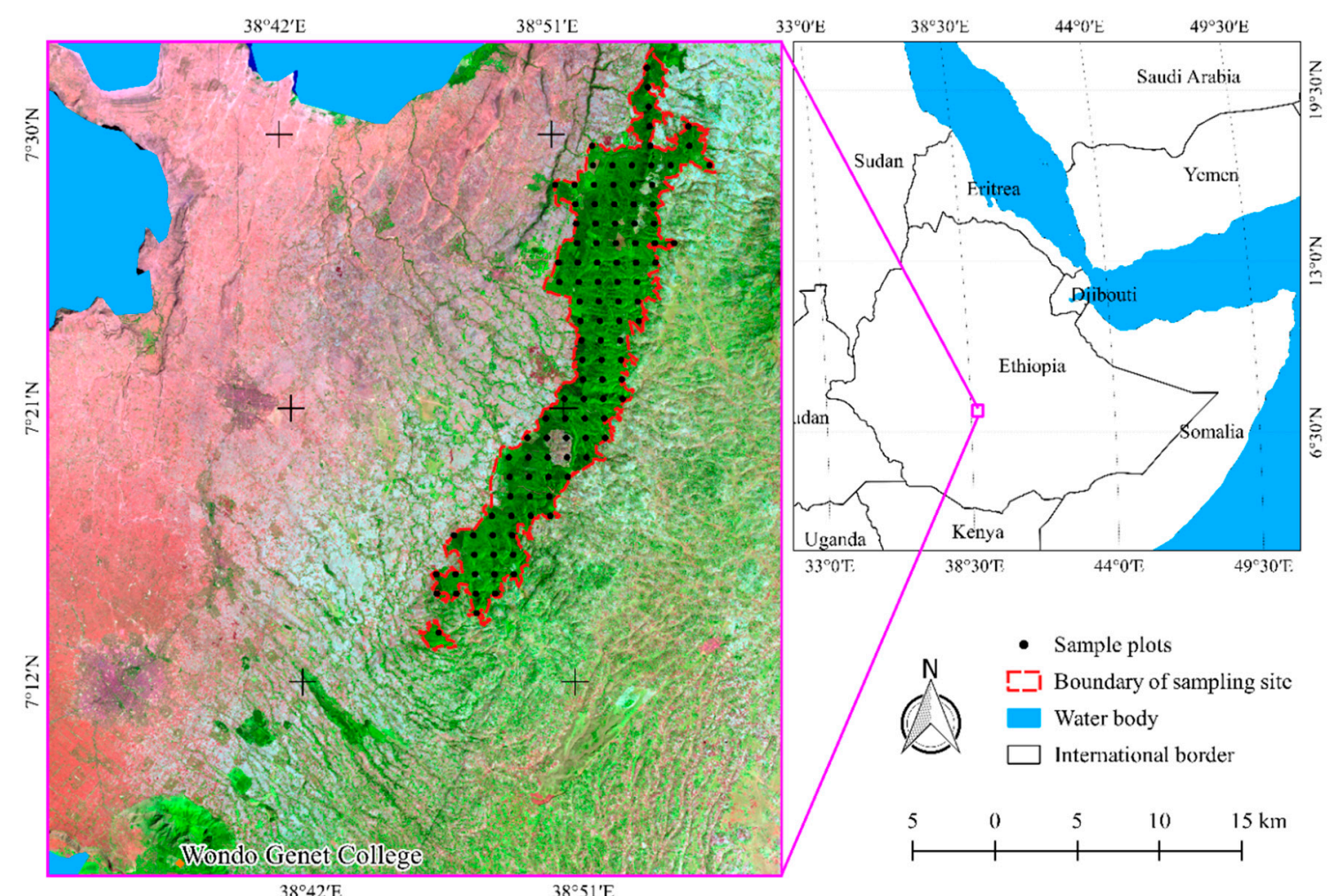

Figure 1. Location of the study area and distribution of the field sample plots (SPs). A band combination of SWIR-NIR-R (in the order of R-G-B) of L8 image was used to enhance the appearance of vegetated areas (in green).

The forest area has both natural and plantation forest types. The major species of plantation forest compartments, which are mostly found in the lower elevations, are Cupressus lucitanica, Pinus patula, Grevillea robusta and different Eucalyptus species. The natural forest has high tree species diversity. The dominant tree species observed in the natural forest include Syzygium guineense, Afrocarpus falcatus, Juniperus procera, Pitosporum viridiflorum, Maesa lanceolate, Millettia ferruginea, Croton macrostachyus and Maytenus arbutifolia. The objectives of the enterprise are the production of lumber and poles from the plantations and conserving the natural forests. The natural forests are home to a wide range of wildlife species and are sources of water for the downstream areas. Nevertheless, the forests are under severe pressure. Illegal cutting of trees and land-use change for settlement and farmland expansion are the common problems in the area.

The forest has complex vertical and horizontal structures. Besides the species diversity, there is large variability in tree height and wood basic density of the study forest. The mean (and range) of 
observed tree height was $13.90 \mathrm{~m}(4.90-40.10 \mathrm{~m})$; while the mean (and range) of wood basic density $\left(\mathrm{g} \mathrm{cm}^{-3}\right)$ for tree species in the forest was $0.59(0.43-0.98)$ [42].

\subsection{Field Data Collection}

The sampling frame was defined to include the Degaga-Gambo forest territory, which contains both the natural and plantation forest types. Circular sample plots (SPs) of $17.85 \mathrm{~m}$ radius aligned in a systematic grid at an interval of $1.18 \mathrm{~km}$ were used for field data collection (Figure 1). One hundred and eleven plots (from the natural forests, plantation forests and other categories like clear-cut, cropland, settlement and grassland cover types) were sampled from February 2018 to January 2019. Handheld global positioning system (GPS) receiver was used to navigate to the pre-defined locations of the SPs. Then, the precise coordinates of the plot centers were determined using differential GPS and global navigation satellite system (GLONASS) measurements. Two Topcon legacy-E + 40 dual-frequency receivers were used for this purpose [43]; one serving as a base station and the other as a rover field unit. The receivers record pseudo-range and carrier phase of GPS and GLONASS.

The base station was set up at Wondo Genet College of Forestry and Natural Resources campus. The Euclidean distance between the base station and the plot centers ranged between 21.70 and $57.20 \mathrm{~km}$ with an average distance of $41.80 \mathrm{~km}$. To determine the position of the base station using precise point positioning, the GPS and GLONASS data were recorded continuously for $24 \mathrm{~h}$ [44]. At the plot centers, the rover was mounted on a $2.98 \mathrm{~m}$ carbon rod and recorded for $41.50 \mathrm{~min}$ on average using a one-second logging rate. The recordings were post-processed using the Magnet tools software [45]. The standard error of the post-processed planimetric plot coordinates ranged from 0.02 to $1.11 \mathrm{~m}$ with a mean of $0.23 \mathrm{~m}$.

In each of the SPs, we recorded species names and measured DBH, i.e., the diameter of trees at $1.3 \mathrm{~m}$ above the ground, for all the trees with $\mathrm{DBH} \geq 5 \mathrm{~cm}$. Caliper or diameter tape was used for DBH measurement depending on tree size. Tree height measurements were carried out for 10 trees selected systematically in each of the plots using a Haglöf vertex laser 5 instrument [46]. Heights of the trees for which height was not measured were predicted using height-diameter models developed based on the sample trees $[16,19,47]$.

\subsection{Plot-Level AGB Estimation}

Plot-level AGB was estimated by aggregating the predicted individual tree AGB in the respective plots. For predicting tree AGB in the natural forests, the allometric model constructed by [42] was used. This model has DBH, height and wood basic density as predictor variables. Wood basic density values were obtained from [48]. For plantation forests, tree AGB was estimated using species-specific allometric models. Accordingly, for Cupressus lusitanica, we used the model by [49] with DBH and height as predictor variables. For Eucalyptus species and Grevillea robusta, models by [50,51] were used, respectively, having DBH and height as predictor variables. The plot-level AGB data in units of $\mathrm{kg} \mathrm{m}^{-2}$ were converted to $\mathrm{Mg} \mathrm{ha}^{-1}$ (megagrams per hectare) since the data were collected from large plots $\left(1000 \mathrm{~m}^{2}\right)$. The plot-level AGB values ranged from 0 to $845.70 \mathrm{Mg} \mathrm{ha}^{-1}$ with a mean and standard deviation of $184.35 \mathrm{Mg} \mathrm{ha}^{-1}$ and $155.10 \mathrm{Mg} \mathrm{ha}^{-1}$, respectively.

\subsection{Satellite Image Acquisition}

Satellite images acquired in January 2019 were considered since this is the dry season when most of the undergrowth vegetation dries up and is easier to distinguish from the trees. This time window was also within the field inventory period. Additionally, selected images were restricted to those with cloud cover $<5 \%$. A detail description of the images used in this study is given in Table 1 .

Single tiles of each of the L8 and S2 products were downloaded from the USGS Earth Explorer website [52]. Both images were Level-1C products, which means that the images were corrected for any possible topographic and geometric errors. The processing level of the L8 image used in this study was L1-TP, which is a Level-1 precision and terrain corrected product. Besides terrain and topographic 
correction, radiometric correction has already been done for S2 products before delivery. The SBs used in this study (i.e., blue (B), green (G), red (R), near-infrared (NIR), shortwave infrared-1 (SWIR1) (for both L8 and S2), red-edge (RE) (only for S2)) have spatial resolutions of $30 \mathrm{~m}$ for L8 and 10 or $20 \mathrm{~m}$ for S2 (see Table 1 for details of the resolutions of individual bands).

We downloaded the PS Ortho Scene Product (Level-3B) from the Planet Explorer website [53]. Six scenes of orthorectified scaled Top of Atmosphere Radiance (at sensor) images were downloaded to cover the study area. These images contain information about the B, G, R and NIR SBs.

Table 1. Major characteristics of Landsat-8 (L8), Sentinel-2 (S2) and PlanetScope (PS) systems and properties of images used in this study.

\begin{tabular}{|c|c|c|c|c|c|c|c|}
\hline Satellite & Sensor $^{a}$ & $\begin{array}{l}\text { Path/Row or } \\
\text { Tile Number }\end{array}$ & $\begin{array}{c}\text { Date of } \\
\text { Acquisition }\end{array}$ & $\begin{array}{c}\text { Cloud Cover } \\
(\%)\end{array}$ & $\begin{array}{c}\text { Product } \\
\text { Processing } \\
\text { Level }\end{array}$ & $\begin{array}{l}\text { Spectral } \\
\text { Bands }\end{array}$ & $\begin{array}{c}\text { Spatial } \\
\text { Resolution }\end{array}$ \\
\hline L8 & OLI & $168 / 055$ & $\begin{array}{l}\text { 16 January } \\
2019\end{array}$ & 0 & L1-TP & $\begin{array}{l}\text { B, G, R, NIR, } \\
\text { SWIR1 }\end{array}$ & $30 \mathrm{~m}$ : all SB \\
\hline S2 & MSI & T37NDJ & $\begin{array}{l}14 \text { January } \\
2019\end{array}$ & 3 & Level-1C & $\begin{array}{l}\text { B, G, R, RE, } \\
\text { NIR, SWIR1 }\end{array}$ & $\begin{array}{l}10 \text { m: visible, } \\
\text { NIR; } 20 \text { m: RE, } \\
\text { SWIR1 }\end{array}$ \\
\hline PS & $\begin{array}{l}\text { 4-band frame } \\
\text { imager; NIR } \\
\text { filter }\end{array}$ & $\begin{array}{l}\text { Scene-based } \\
\text { frames }\end{array}$ & $\begin{array}{l}27 \text { January } \\
2019\end{array}$ & 0 & 3B-Analytic-MS & B, G, R, NIR & $3 \mathrm{~m}$ : all SB \\
\hline
\end{tabular}

Source: USGS Earth Explorer [52] for L8 and S2; Planet Explorer [53] for PS. ${ }^{a}$ OLI and MSI stand for operational land imager and multispectral instrument sensors of L8 and S2, respectively. ${ }^{b}$ B, G, R, NIR, SWIR1 and RE represent the blue, green, red, near-infrared, shortwave infrared-1 and red-edge spectral bands (SBs), respectively.

\subsection{Image Processing and Independent Variable Definition}

In the current study, we first evaluated a great number of potential candidate variables that could be useful for AGB modelling. A series of image processing techniques were applied to the satellite images to get the independent variables. First, atmospheric correction was done using the QGIS software version 3.1.0 [54] and python codes. For L8 and S2 images, the semi-automatic classification plugin (SCP) of QGIS was used for running the dark-object subtraction (DOS-1) algorithm, which removes the dark pixels that result from atmospheric scattering. The satellite images were transformed from spectral radiance to top of atmosphere reflectance values based on the conversion factors in the metadata file that comes along with the image files. However, the PS images were processed using the empirical line correction for conversion of radiance to reflectance values indicated in Equation (1):

$$
\text { Reflectance }=\text { coefficient } \times \text { Radiance (Input data) }
$$

The radiances of the input images were converted to reflectance values and atmospheric correction applied since variables from multiple images were compared. In addition to variation in the sensors, the three sets of images were acquired on different dates although within 13 days of maximum gap among them. Furthermore, six scenes of the PS imagery covered the area of interest. After atmospheric correction, all the images became Level-2A products, which have pixels with surface reflectance values suitable for calculating SIs and texture variables used in this study. Atmospherically corrected SBs, which were used for creating SIs and texture variables shown in Table 2 and Table 3, respectively, were selected for this study. 
Table 2. Description of spectral indices (SIs) used as candidate independent variables for aboveground biomass (AGB) modelling in this research.

\begin{tabular}{|c|c|c|c|}
\hline \multirow{2}{*}{ SI } & \multirow{2}{*}{ Expression $^{c}$} & \multicolumn{2}{|r|}{ Reference(s) } \\
\hline & & General & Relationship with AGB \\
\hline NDVI & $\frac{(\mathrm{NIR}-\mathrm{R})}{(\mathrm{NIR}+\mathrm{R})}$ & {$[55,56]$} & {$[19,30]$} \\
\hline SR & NIR/R & [57] & {$[30,34]$} \\
\hline VI & $\mathrm{G} / \mathrm{R}$ & [58] & \\
\hline DVI & NIR - R & [59] & [30] \\
\hline ExGI & $2 \times G-(B+R)$ & & \\
\hline GLI & $\frac{(G-R)+(G-B)}{2 \times G+R+B}$ & [60] & \\
\hline EVI & $2.5 \times \frac{(\mathrm{NIR}-\mathrm{R})}{(\mathrm{NIR}+6 \times \mathrm{R}-7.5 \times \mathrm{B}+1)}$ & [61] & [19] \\
\hline SAVI & $\frac{(\mathrm{NIR}-\mathrm{R})}{(\mathrm{NIR}+\mathrm{R}+0.5)} \times(1.5)$ & [62] & [30] \\
\hline MSAVI & $2 \times \mathrm{NIR}+1-\left(\sqrt{(2(\mathrm{NIR})+1)^{2}-8(\mathrm{NIR}-\mathrm{R})}\right)$ & [63] & [30] \\
\hline NDMI & $\frac{(\text { NIR-SWIR1 })}{(\text { NIR+SWIR1) }}$ & [64] & [19] \\
\hline NDGI & $\frac{(\mathrm{G}-\mathrm{R})}{(\mathrm{G}+\mathrm{R})}$ & [36] & \\
\hline ARVI & $\frac{(\mathrm{NIR}-(2 \times \mathrm{R}-\mathrm{B}))}{(\mathrm{NIR}+(2 \times \mathrm{R}-\mathrm{B}))}$ & [65] & [22] \\
\hline SRRE & NIR/RE & {$[66,67]$} & [26] \\
\hline RENDVI & $\frac{(\mathrm{NIR}-\mathrm{RE})}{(\mathrm{NIR}+\mathrm{RE})}$ & {$[68]$} & [35] \\
\hline
\end{tabular}

c See Table 1 for description of the acronyms of the SBs used in the expressions of the SIs in this table.

Table 3. General description of the grey level co-occurrence matrix (GLCM) texture features used in this study.

\begin{tabular}{|c|c|c|}
\hline GLCM Texture $^{\mathrm{d}}$ & Expression $^{\mathrm{e}}$ & Description \\
\hline Contrast & $\sum_{i, j=0}^{N-1} p_{i, j} \times(i-j)^{2}$ & \multirow{2}{*}{$\begin{array}{l}\text { Contrast and dissimilarity indicate the amount } \\
\text { of local grey level (GL) variation in an image. } \\
\text { Large values indicate the presence of edges, } \\
\text { noise or wrinkled features. }\end{array}$} \\
\hline Dissimilarity & $\sum_{i, j=0}^{N-1} p_{i, j} \times|i-j|$ & \\
\hline Homogeneity (IDM) & $\sum_{i, j=0}^{N-1} \frac{p_{i, j}}{1+(i-j)^{2}}$ & $\begin{array}{l}\text { Measures the smoothness (homogeneity) of the } \\
\text { GL distribution of an image. }\end{array}$ \\
\hline ASM & $\sum_{i, j=0}^{N-1}\left(p_{i, j}\right)^{2}$ & $\begin{array}{l}\text { ASM measures the degree of orderliness of } \\
\text { pixel values in an image. }\end{array}$ \\
\hline Energy & $\sqrt{\mathrm{ASM}}$ & Energy is a measure of uniformity. \\
\hline Maximum probability & $\operatorname{maximum}\left(\mathrm{p}_{\mathrm{i}, \mathrm{j}}\right)$ & Maximum probability of the GL values. \\
\hline Entropy & $\sum_{i, j=0}^{N-1} p_{i, j} \times\left(-\ln ^{p_{i, j}}\right)$ & $\begin{array}{l}\text { It measures the degree of randomness of pixel } \\
\text { values in an image. Entropy is inversely related } \\
\text { to uniformity. }\end{array}$ \\
\hline GLCM mean & $\mu_{\mathrm{i}}=\sum_{\mathrm{i}, \mathrm{j}=0}^{\mathrm{N}-1} \mathrm{i} \times\left(\mathrm{p}_{\mathrm{i}, \mathrm{j}}\right) ; \mu_{\mathrm{j}}=\sum_{\mathrm{i}, \mathrm{j}=0}^{\mathrm{N}-1} \mathrm{j} \times\left(\mathrm{p}_{\mathrm{i}, \mathrm{j}}\right)$ & Mean of GL distribution of the image. \\
\hline GLCM variance & $\begin{array}{l}s_{i}^{2}=\sum_{i, j=0}^{N-1} p_{i, j} \times\left(i-\mu_{i}\right)^{2} \\
s^{2}{ }_{j}=\sum_{i, j=0}^{N-1} p_{i, j} \times\left(j-\mu_{j}\right)^{2}\end{array}$ & $\begin{array}{l}\text { GLCM variance is a measure of the dispersion } \\
\text { of GL distribution. }\end{array}$ \\
\hline Correlation & $\sum_{i, j=0}^{N-1} p_{i, j} \times\left[\frac{\left(i-\mu_{i}\right) \times\left(j-\mu_{j}\right)}{\sqrt{s^{2} \times s^{2}}}\right]$ & $\begin{array}{l}\text { Correlation indicates the linear dependency of } \\
\text { GL on their neighboring pixels. }\end{array}$ \\
\hline \multicolumn{3}{|c|}{$\begin{array}{l}\text { IDM and ASM stand for inverse difference moment and angular second moment, respective } \\
\text { Vhere } p_{i, j} \text { is the probability of finding the GLCM relationship at cell }(i, j) \text { and is calculated as } p_{i, j}=\frac{V_{i, j}}{\sum_{i, j=0}^{N-1} V_{i} \text {, }}\end{array}$} \\
\hline
\end{tabular}

Table 2 shows the expressions used to derive spectral index values from each satellite image type used in this study and references to scientific evidences on the use of the indices in general and for biomass estimation in particular.

Descriptions of the GLCM image texture data derived from the PS images are presented in Table 3. Texture information of the L8 and S2 images were not used due to the coarse spatial resolutions. Sentinel Application Platform (SNAP) software version 7.0.0 [69] was used for calculating the texture variables. Processing parameters of window size of $11 \times 11$ pixels, angle in all directions, 
probability quantization with level of 128 were set to obtain the texture data used in the current study. This processing window size was set to provide an equivalent area to the field SPs.

Area-weighted mean and standard deviation (hereafter referred to as mean and standard deviation, respectively) of all the variables were extracted to each SP using QGIS. These were used as independent variables of the models constructed from each RS data type, the details of which are explained in the following sections.

\subsection{Variable Selection and Model Fitting}

The purpose of the AGB regression modelling was to construct models with variables from the RS data as predictors and which could be used to enhance the precision of the overall AGB estimates for the study area. For the AGB estimation, we used a model-assisted approach to inference (see details in Section 2.8) because that would allow a direct comparison of the uncertainty of the AGB estimate with similar uncertainty estimates obtained for the pure field-based estimate. In model-assisted estimation, the model form and the predictors selected for the model should be determined independent of the sample at hand [70]. In model-assisted inference, no claim of a true model is necessary. A poor choice of model form and predictors would have negative consequences in terms of efficiency [71] (p. 238), but would not invalidate the unbiasedness of the estimator. If, however, the choice of model form and the choice of predictors were sample-based, e.g., by choosing predictors by optimizing the predictive power of the model for the sample at hand, there would be a risk of overfitting and underreporting of uncertainty [72].

On this background, we found ourselves in a dilemma in this study. On one hand, we had no prior information about useful variables derived from the given RS data for AGB modelling for the particular forest types under study. Neither had we any experience with suitable model forms for the study area. On the other hand, if model selection and variable selection were optimized for the given sample, overfitting would be a likely consequence.

To balance these conflicting requirements, we first did a screening of the variables mentioned above to gain first-hand experience with the three types of satellite data for the current forest types. We then chose a model-form a priori, and allowed only a small number of predictors to be included in the model. In the modelling phase, we paid special attention to any sign of overfitting.

Thus, in the first phase of the analysis, Pearson's correlation coefficient was used to explore the relationships of individual independent variables with AGB. Those variables that had a significant correlation with AGB were used as potential variables for the AGB model fitting. Furthermore, correlation analysis was done for each pair of independent variables within each satellite data source to evaluate the level of intercorrelation between them. Results of the correlation analysis indicated that most of the variables were strongly intercorrelated (Figure 2). Hence, variable screening was employed to reduce the redundant information emanating from those strongly intercorrelated variables. Results of the initial analysis using more complex models showed overfitting problems, which was manifested in precision difference between training and validation results for each model. Such severe overfitting was observed for models with more than two variables. Because of the risk of overfitting, we restricted the selection of independent variables in the models to a maximum of two variables only. The results from the analysis of models with more than two variables are not documented any further. 


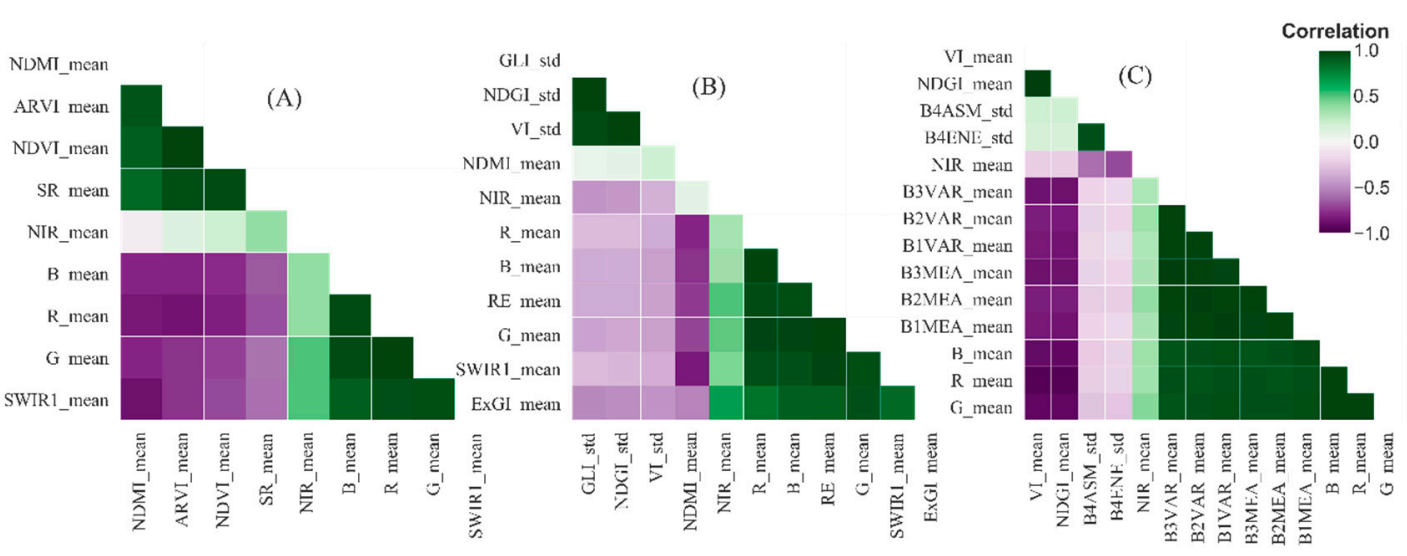

Figure 2. Intercorrelation among independent variables derived from (A) L8, (B) S2, and (C) PS images. See Table 4 for the descriptions of the notations used to represent the independent variables.

Table 4. Correlation of relevant independent variables (see Tables 1-3 for definitions) derived from L8, S2 and PS images with AGB. The notations for SB and SI variables of all the image types are MMM_mean or MMM_std representing the mean and standard deviation of the variable MMM, in respective order. For texture variables of the PS data, BnXXX_mean is the mean of the mentioned (XXX) texture variable of the SB Bn where $n=1,2,3,4$ for B, G, R, NIR, respectively. Similarly, BnXXX_std is the standard deviation of the texture variable as described above for the BnXXX_mean, except replacing 'mean' by 'std'. VAR and MEA stand for the GLCM variance and mean, respectively.

\begin{tabular}{cccccc}
\hline \multicolumn{2}{c}{ L8 } & \multicolumn{3}{c}{ S2 } & \multicolumn{2}{c}{ PS } \\
\hline Variable & Correlation & Variable & Correlation & Variable & Correlation \\
\hline NDMI_mean & $0.39^{* * *}$ & GLI_std & $0.44^{* * *}$ & VI_mean & $0.44^{* * *}$ \\
ARVI_mean & $0.27^{* *}$ & NDGI_std & $0.43^{* * *}$ & NDGI_mean & $0.44^{* * *}$ \\
NDVI_mean & $0.23^{*}$ & VI_std & $0.43^{* * *}$ & B4ASM_std & $0.37^{* * *}$ \\
SR_mean & $0.19^{*}$ & NDMI_mean & $0.31^{* * *}$ & B4ENE_std & $0.35^{* * *}$ \\
NIR_mean & $-0.38^{* * *}$ & NIR_mean & $-0.42^{* * *}$ & NIR_mean & $-0.38^{* * *}$ \\
B_mean & $-0.41^{* * *}$ & R_mean & $-0.43^{* * *}$ & B3VAR_mean & $-0.39^{* * *}$ \\
R_mean & $-0.42^{* * *}$ & B_mean & $-0.46^{* * *}$ & B2VAR_mean & $-0.39^{* * *}$ \\
G_mean & $-0.45^{* * *}$ & RE_mean & $-0.48^{* * *}$ & B1VAR_mean & $-0.39^{* * *}$ \\
SWIR1_mean & $-0.48^{* * *}$ & G_mean & $-0.49^{* * *}$ & B3MEA_mean & $-0.40^{* * *}$ \\
& & SWIR1_mean & $-0.49^{* * *}$ & B2MEA_mean & $-0.40^{* * *}$ \\
& & ExGI_mean & $-0.51^{* * *}$ & B1MEA_mean & $-0.40^{* * *}$ \\
& & & & B_mean & $-0.46^{* * *}$ \\
& & & R_mean & $-0.46^{* * *}$ \\
& & & G_mean & $-0.48^{* * *}$ \\
\hline
\end{tabular}

${ }^{*} p$-Value $<0.05 ;{ }^{* *} p$-value $<0.01 ;{ }^{* * *} p$-value $<0.001$

The relevant variables of each satellite data source were related to plot-level AGB using the logarithmic link function in a generalized linear model (GLM) of the form:

$$
\ln \left(y_{i}\right)=\beta_{0}+\sum_{i=1}^{i} \beta_{i} x_{i}
$$

where $y_{\mathrm{i}}$ is ground reference AGB $\left(\mathrm{Mg} \mathrm{ha}^{-1}\right), \beta_{0}$ is intercept, $\beta_{\mathrm{i}}$ is the coefficient of the independent variable $\left(X_{i}\right)$, and $i$ is the index of an individual independent variable.

This model form was chosen since it provides valid estimates where true zeroes are included in the estimate of AGB, which has positive continuous numerical values. A study of AGB prediction using topographic variables in human-impacted tropical dry forest landscapes of Mexico indicated that GLM estimation technique improved predictions [73]. Thus, the mean of SBs and SIs of L8 image were candidate independent variables for the L8 model. The mean and standard deviation of the SBs and SIs of the S2 image were candidate independent variables for the S2 model. The mean and standard 
deviation of SBs, SIs and texture features of PS bands were used as candidate independent variables for the PS model.

\subsection{Model Validation}

We evaluated the performance of the models using a leave-one-out-cross validation technique. The cross-validation was used to assess overfitting. Each model was validated in terms of coefficient of determination $\left(\mathrm{R}^{2}\right)$, root mean squared error (RMSE, \%), mean deviation (MD, \%), and Akaike Information Criterion (AIC) as determined by Equations (3)-(8). The AIC was used to evaluate the maximum likelihood of the model parameters. The maximum likelihood estimation enables choosing the parameter that makes the likelihood of having the observed data a maximum fit with the dependent variable (AGB) without causing an overfitting issue. When comparing models, the model with a smaller AIC is better than the one with a higher AIC.

$$
\begin{gathered}
\mathrm{R}^{2}=1-\frac{\text { Residual deviance }}{\text { Null deviance }} \\
\text { RMSE }=\sqrt{\frac{1}{n} \sum_{\mathrm{i}=1}^{\mathrm{n}}\left(\mathrm{y}_{\mathrm{i}}-\hat{\mathrm{y}}_{\mathrm{i}}\right)^{2}} \\
\mathrm{RMSE} \%=\frac{\mathrm{RMSE}}{\overline{\mathrm{y}}} \times 100 \\
\mathrm{MD}=\frac{1}{\mathrm{n}} \sum_{\mathrm{i}=1}^{\mathrm{n}}\left(\mathrm{y}_{\mathrm{i}}-\hat{\mathrm{y}}_{\mathrm{i}}\right) \\
\mathrm{MD} \%=\frac{\mathrm{MD}}{\overline{\mathrm{y}}} \times 100 \\
\mathrm{AIC}=-2 \ln \mathrm{L}[\hat{\beta}(\mathrm{k})]+2 \mathrm{k}
\end{gathered}
$$

where $y_{i}$ and $\hat{y}_{i}$ are the ground reference and predicted AGB $\left(\mathrm{Mg} \mathrm{ha}^{-1}\right)$ in the ith SP; $\bar{y}$ is the mean of ground reference AGB $\left(\mathrm{Mg} \mathrm{ha}^{-1}\right)$ of all SPs; $n$ is the sample size; $L[\hat{\beta}(\mathrm{k})]$ is the likelihood function of the observations, $\hat{\beta}(\mathrm{k})$ is the maximum likelihood estimation of the parameter $\beta$ given the number of parameters of $\mathrm{k}$ within the model.

In addition to the validation metrics indicated above, we did qualitative evaluation based on a visual comparison between the predictions using the selected models in each satellite data source and false-color composite (i.e., band combination of NIR-R-G in the R-G-B channels) depiction of the S2 image.

\subsection{Population-Level Estimation and Efficiency Assessment}

Based on the SP inventory data, for the sample size of 111 plots of about $1000 \mathrm{~m}^{2}$ area, the estimators of the mean AGB for the population and its variance were calculated by Equation (9) and Equation (10), respectively [71]:

$$
\begin{gathered}
\hat{\mu}_{\text {field }}=\frac{1}{n} \sum_{i=1}^{n} y_{i} \\
\operatorname{vâr}\left(\hat{\mu}_{\text {field }}\right)=\frac{1}{n(n-1)} \sum_{i=1}^{n}\left(y_{i}-\hat{\mu}_{\text {field }}\right)^{2}
\end{gathered}
$$

where $\mathrm{y}_{\mathrm{i}}$ is AGB $\left(\mathrm{Mg} \mathrm{ha}^{-1}\right)$ of the ith SP in the sample and $\mathrm{n}$ is the sample size.

The $95 \%$ confidence interval (CI) of $\hat{\mu}_{\text {field }}$ was calculated using Equation (11):

$$
\mathrm{CI}=\hat{\mu}_{\text {field }} \pm \mathrm{t} \times \mathrm{SE}\left(\hat{\mu}_{\text {field }}\right)
$$


where $\mathrm{SE}\left(\hat{\mu}_{\text {field }}\right)=\sqrt{\operatorname{vâr}\left(\hat{\mu}_{\text {field }}\right)}$ is the standard error (SE) of $\hat{\mu}_{\text {field }}$ and $t$ is student's $t$ at a significance level of 0.05 .

Similarly, we estimated the mean AGB for the entire study area using the selected regression model for each satellite data source. For this purpose, the study area was tessellated into grid cells of $31.64 \times 31.64 \mathrm{~m}$ providing a total of $\mathrm{N}(141,604)$ population units. The size of the grid cells was chosen to be equivalent to that of the SPs. Area-weighted mean and standard deviation of the variables used in the regression models were extracted for each grid cell using QGIS. AGB was predicted for each population unit (i) in the map of the tessellated granules using the selected regression models for each satellite data source and is represented by $\hat{y}_{i}$. Because the prediction relied on field data collected based on probability sampling inside the population of interest, we adopted generalized model-assisted regression estimators. The mean and the variance estimates were computed using Equation (12) and Equation (13), respectively [71] (p. 231):

$$
\hat{\mu}_{\text {image }}=\frac{1}{N} \sum_{i=1}^{N} \hat{y}_{i}+\frac{1}{n} \sum_{i=1}^{n}\left(y_{i}-\hat{y}_{i}\right)
$$

where $\hat{\mu}_{\text {image }}$ is the mean remote sensing-assisted estimate of AGB (either L8, S2 or PS). The first term in this estimator $\left(\frac{1}{\mathrm{~N}} \sum_{\mathrm{i}=1}^{\mathrm{N}} \hat{\mathrm{Y}}_{\mathrm{i}}\right)$ is the mean of the model predictions $\left(\hat{\mathrm{y}}_{\mathrm{i}}\right)$ for all population units, and the second term $\left(\frac{1}{n} \sum_{i=1}^{n}\left(\hat{y}_{i}-y_{i}\right)\right)$ is an estimate of the mean error calculated over the sample units and compensates for systematic model prediction errors.

$$
\operatorname{vâr}\left(\hat{\mu}_{\text {image }}\right)=\frac{1}{\mathrm{n}(\mathrm{n}-1)} \sum_{\mathrm{i}=1}^{\mathrm{n}}\left(\varepsilon_{\mathrm{i}}-\bar{\varepsilon}\right)^{2}
$$

where $\varepsilon_{\mathrm{i}}$ and $\bar{\varepsilon}$ are the estimates of error at each data point (i) and the average, respectively.

The SE of the mean AGB estimators (i.e., $\operatorname{SE}\left(\hat{\mu}_{\text {field }}\right)$ and $\left.\operatorname{SE}\left(\hat{\mu}_{\text {image }}\right)\right)$ were calculated by taking the square root of the respective variance estimators vâr $\left(\hat{\mu}_{\text {field }}\right)$ and vâr $\left(\hat{\mu}_{\text {image }}\right)$.

The study assessed the gain in precision of AGB estimation with the use of the three types of RS data. The measure of quantifying such a gain in precision of using RS data over the pure field-based estimates was expressed using relative efficiency (REf). REf quantifies the magnitude of estimated variance of a remote sensing-assisted estimate of mean AGB to a field-based estimate. It was computed by Equation (14) as the ratio of the variance of the field-based estimates to the remote sensing-assisted estimates:

$$
\operatorname{REf}=\frac{\operatorname{vâr}\left(\hat{\mu}_{\text {field }}\right)}{\operatorname{vâr}\left(\hat{\mu}_{\text {image }}\right)}
$$

When REf is greater than one, it is interpreted as the amount of additional precision gained due to the use of the RS data for estimating mean AGB.

\section{Results}

\subsection{Relationship of Independent Variables with AGB}

Statistical test for significance of correlation coefficients of the relationship of individual RS variables with AGB demonstrated that many of the candidate variables were reasonably related to AGB. Correlation coefficients were translated to descriptors like 'weak', 'moderate' and 'strong' relationships according to the scheme used by [74]. The mean SB reflectance values of the three satellite data sources had negative moderate correlation with AGB (Table 4). On the other hand, the mean values of most SIs tend to show moderate positive relationships with AGB with some exceptions (for instance, mean ExGI of S2). It was revealed from the exploratory analysis that standard deviation of SIs of S2 and PS images and texture variables of PS images had moderate relationships with AGB. 
For the L8 category of independent variables, the mean SIs were less correlated with AGB as compared to those of the SBs. Table 4 shows that from the SIs, the mean NDMI had considerable relationship while that of ARVI, NDVI and SR have weaker performance. The mean values of all SBs were moderately related to AGB with correlation coefficients ranging from -0.38 (NIR_mean) to -0.48 (SWIR1_mean). The strength of the association of AGB with NIR_mean was equivalent to that observed with the strongly correlated SI (i.e., the NDMI_mean), which was 0.39 .

From the S2 variables, the mean of both SBs and SIs showed reasonable association with AGB. Similar to the L8 variables, the mean of SBs had a stronger relationship than that of the SIs except the mean ExGI, which had the strongest relationship. The peculiar behavior of ExGI comes from the fact that it is just a difference of SBs. Likewise; the standard deviation of the SIs (namely GLI, NDGI and VI) had strong positive associations with the dependent variable.

Similarly, for the PS variables, the mean of SBs of G, R and B showed the strongest relationship with AGB followed by that of VI and NDGI SIs. The mean and standard deviation of the texture data had moderate relationships with AGB (Table 4).

\subsection{Variable Selection for the Prediction Models}

Correlation analysis indicated that independent variables of each satellite data source were strongly intercorrelated (Figure 2). Therefore, the variables that fit well with AGB in the GLM, and which had no significant collinearity problem, were selected for the AGB prediction models. As a result, the means of NDMI and NIR variables were less intercorrelated and became predictor variables for one of the L8 models. Besides, a simple model with the most strongly correlated variable (SWIR1) with AGB was considered as another candidate model in this category.

Similarly, the mean of SWIR1 and standard deviation of GLI were selected as predictor variables for the two-variable S2 model. The standard deviation of GLI had a strong positive correlation with AGB (Table 4) and was less correlated with the mean of SWIR1 variable (Figure 2), which was already in the model. Moreover, the single variable model with a predictor variable of mean of ExGI and another one with the mean of SWIR1 SB were other candidate models of the S2 category.

From the PS data, the mean of $G$ reflectance had the strongest correlation with AGB. Thus, one of the PS models contains independent variables composed of the mean reflectance of G SB and the standard deviation of the ASM texture variable of the NIR SB. The mean of B4ASM was the least intercorrelated with the mean of G SB. The other simple model was the model with a predictor variable of the mean of G SB reflectance only.

\subsection{Selected AGB Models for Each Image Type}

Table 5 shows a detailed description of the candidate AGB models for each image type. Two candidate models were obtained from the L8 data. There was a marginal difference between the single and two-variable models with AIC of 1403.31 and 1402.68, respectively. The model calibration RMSE of the single and two-variable models were $70.22 \%$ and $71.06 \%$ of the mean AGB, respectively. Likewise, the respective model validation RMSE values were $73.23 \%$ and $73.31 \%$ of the mean AGB. As clearly revealed in these model metrics, there is concern of less responsiveness of the selected variables for the AGB estimates in the two-variable model. The presence of two variables in the model did not significantly improve the model performance. Therefore, the model with the mean of SWIR1 reflectance as the only predictor variable was selected for AGB estimation.

Three models were selected as candidates from the S2 variables. Two of them were with a single predictor variable while the third has two variables (Table 5). The model with the mean of ExGI as a predictor variable had a larger validation RMSE (73.80\%) than the other models. The model with the predictor variable of the mean of SWIR1 was better than the one with the mean of ExGI. However, the two-variable model had even greater performance among the S2 category of models. The two-variable S2 model with predictor variables of the mean of SWIR1 and standard deviation of GLI had the least AIC value among the models (1385.06) and minimal overfitting problem (Table 5). 
Additional indicators of the model fit and validation results of this model were better than the other models in the category. This model explained $40.96 \%$ of the variability in the ground reference AGB unlike the selected L8 and PS models, each of which explained less than $30 \%$.

Two candidate models were obtained from the PS data. The two-variable PS model contains the mean of $\mathrm{G}$ reflectance and the standard deviation of B4ASM texture as predictor variables. However, this model revealed a severe overfitting problem. The model RMSE and validation RMSE were 70.19\% and $79.48 \%$, respectively. Thus, the single-variable model with the mean of G reflectance was selected for AGB estimation in this category. It had model calibration and validation RMSE of $71.79 \%$ and $75.17 \%$, respectively. Overall performance of the selected PS model was slightly lower than the selected S2 model but similar to that of the selected L8 model (Table 5).

The validation results of all the three selected models for AGB estimation indicated that the models have sensible performance in predicting AGB for the data with which they were not trained. The scatter plot of fitted versus ground reference AGB values shown in Figure 3 indicates a reasonable predictive power of the models given the complex settings of the study area. Pearson's correlation coefficients of the model predicted and ground reference AGB in the SPs revealed that the S2 model predictions were more correlated with the ground reference AGB than the other two models. The S2 model predictions had a correlation coefficient of 0.64 with the ground reference AGB.

The L8 and PS models had equivalent performance and explained a considerable amount of the variation in the FBSS estimate of mean AGB with $\mathrm{R}^{2}$ of $29 \%$ and $27 \%$, respectively, given the complex forest structure and topography in the study area.

Although the general trend of the error distribution of the three selected models looks similar, prediction errors of the L8 and PS models spread out at small and large AGB more than the S2 model did (Figure 3). The extents of deviation of predicted values from the ground reference AGB differ for each model especially at the smaller and larger AGB values. With this variability maintained, the selected models of all the three-image data inflated predictions of small AGB, particularly those below approximately $300 \mathrm{Mg} \mathrm{ha}^{-1}$. For SPs with large AGB, the predictions using all the three models were smaller than the ground reference values.

The L8 and S2 models had smaller prediction error at the small AGB end than at the large AGB levels. Generally, the predictive power of the S2 model prevailed over that of the other models.

\subsection{Estimation and Mapping of AGB Using the Selected Models}

Table 6 shows the estimated mean AGB, estimates of mean deviation, SE of the mean AGB estimates and REf for the selected models of the three image categories presented in Table 5. The estimates of mean AGB were $179.67 \mathrm{Mg} \mathrm{ha}^{-1}, 177.79 \mathrm{Mg} \mathrm{ha}^{-1}$ and 184.27 $\mathrm{Mg} \mathrm{ha}^{-1}$ when using the L8, S2 and PS model predictions, respectively. The model-assisted estimates of the mean AGB for all the three categories of models were within 95\% CI of the mean AGB estimate based on the field data only (i.e., 155.15-213.76 $\mathrm{Mg} \mathrm{ha}^{-1}$ ). The estimated mean AGB using the PS model was closer to the field-estimated mean AGB (i.e., $184.35 \mathrm{Mg} \mathrm{ha}^{-1}$ ) than the estimates using the other models. The estimated mean AGB using the L8 and PS models had the largest and smallest MDs, respectively. The AGB estimate based on the PS model was relatively less precise followed by the L8 model. The estimation results revealed that the L8 and PS models resulted in equivalent estimation efficiencies (i.e., 1.40 and 1.37 , respectively). 
Table 5. Models and performance indicators for mean AGB estimation in the Degaga-Gambo forest using independent variables from L8, S2 and PS images.

\begin{tabular}{|c|c|c|c|c|c|}
\hline \multirow{2}{*}{ Image } & \multirow{2}{*}{ Model $^{\mathrm{f}}$} & \multirow{2}{*}{ AIC } & Calibration & Validation & Prediction \\
\hline & & & RMSE (\%) & RMSE (\%) & Correlation $\mathrm{g}$ \\
\hline \multirow{2}{*}{ L8 } & AĜGB $=\exp (6.0703-9.3781 \times$ NIR_mean $+3.5489 \times$ NDMI_mean $)$ & 1402.68 & $129.46(70.22)$ & $135.20(73.31)$ & 0.55 \\
\hline & $A \hat{G B}{ }^{\circledR}=\exp (6.9967-16.1492 \times$ SWIR1_mean $)$ & 1403.31 & $131.00(71.06)$ & $135.00(73.23)$ & 0.54 \\
\hline \multirow{3}{*}{ S2 } & ÂGB ${ }^{\circledR}=\exp (6.1310-11.4874 \times$ SWIR1_mean $+12.7865 \times$ GLI_std $)$ & 1385.06 & $119.58(64.87)$ & $123.70(67.12)$ & 0.64 \\
\hline & Â̂GB $=\exp (7.1200-51.3576 \times$ ExGI_mean $)$ & 1400.00 & $128.97(69.96)$ & $136.01(73.80)$ & 0.56 \\
\hline & Â̂GB $=\exp (6.9968-15.2480 \times$ SWIR1_mean $)$ & 1402.00 & $130.33(70.69)$ & $134.70(73.06)$ & 0.54 \\
\hline \multirow{2}{*}{ PS } & ÂGB $=\exp (10.0593-56.0248 \times$ G_mean $+1.1545 \times$ B4ASM_std $)$ & 1402.55 & $129.40(70.19)$ & $147.30(79.48)$ & 0.55 \\
\hline & ÂG $\mathrm{B}^{\circledR}=\exp \left(11.7696-75.2766 \times \mathrm{G}_{\text {_mean }}\right)$ & 1406.00 & $132.34(71.79)$ & $138.58(75.17)$ & 0.52 \\
\hline
\end{tabular}

${ }_{\mathrm{f}}^{\mathrm{f}}$ Mean and std refer to the area-weighted mean and standard deviation of the image-derived variables within the grid cells. ${ }^{\circledR}$ Selected model for AGB prediction (from each image type). $\mathrm{g}$ Pearson correlation coefficient between ground reference and model-predicted values of AGB for the models in each image type. The square of these coefficients is the same as the $\mathrm{R}^{2}$ of the models, which was determined using Equation (3).
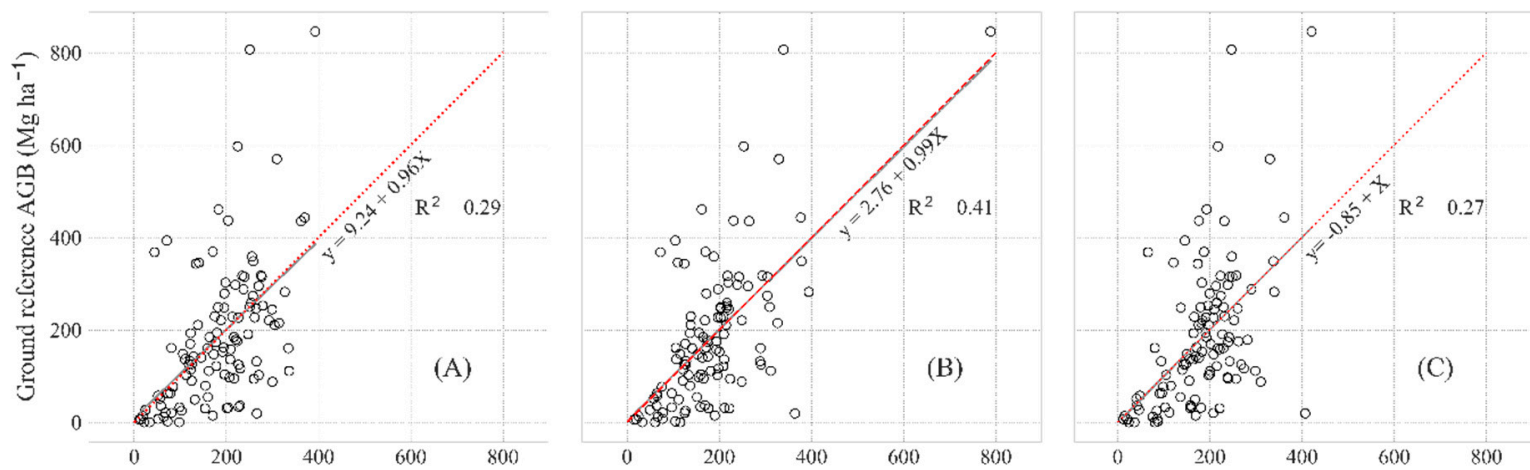

Figure 3. Relationship of ground reference versus predicted AGB using selected models of (A) L8, (B) S2, and (C) PS data. The dashed red and grey solid lines (overlapping) represent the identity (1:1) and the correlation functions, respectively. 
Table 6. Estimated mean AGB ( $\mathrm{Mg} \mathrm{ha}^{-1}$ ), mean deviation (MD) in $\mathrm{Mg} \mathrm{ha}^{-1}$, standard error (SE) of the mean estimates $\left(\mathrm{Mg} \mathrm{ha}^{-1}\right)$ and relative efficiency (REf) when using the selected models to assist in the estimation.

\begin{tabular}{ccccc}
\hline Estimator Data Source & Estimated Mean AGB & Estimated MD & SE & Ref \\
\hline Model-assisted; L8-model & 179.67 & 1.71 & 12.49 & 1.40 \\
Model-assisted; S2-model & 177.79 & 0.62 & 11.40 & 1.68 \\
Model-assisted; PS-model & 184.27 & -0.13 & 12.62 & 1.37 \\
Field-based & 184.35 & - & 14.79 & - \\
\hline
\end{tabular}

The estimate based on the S2 model was the most precise among the three model-assisted AGB estimates with SE of $11.40 \mathrm{Mg} \mathrm{ha}^{-1}$. As a result, the REf of the mean AGB estimate using the S2 model (i.e., 1.68) was greater than what we obtained by using the other two models.

Visual inspection of the predicted AGB using the three selected models and the false-color composite of the S2 image shows convincing AGB distribution across the landscape. As expected, the patches of bare land (non-forest areas) in the study area (shown in different shades of grey in Figure 4D) have small AGB predictions using all the models (shades of yellow in Figure 4A-C) while the dense forest areas (colored red in Figure 4D) yielded greater predicted AGB values (shades of green in Figure 4A-C). The map revealed that AGB predictions using the selected models of the three satellite image types had many similarities, which also was confirmed by similarities in the estimated uncertainties (Table 6). The distribution patterns of AGB predictions in the maps (Figure 4A-C) indicated the spatial consistency of AGB predictions across the area for the selected models.

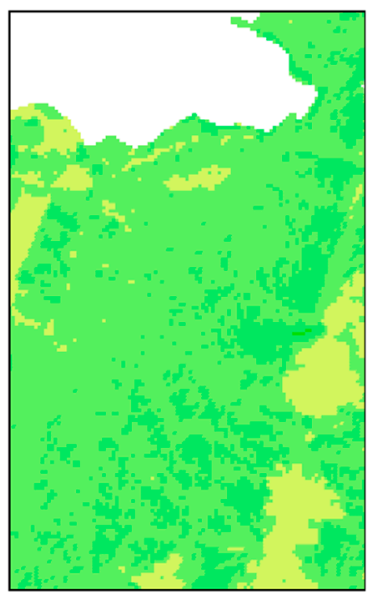

(A)

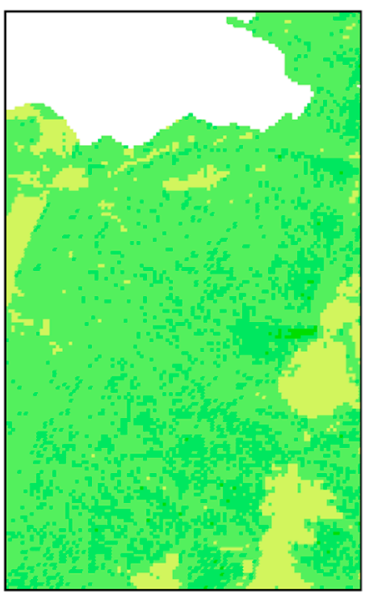

(B)

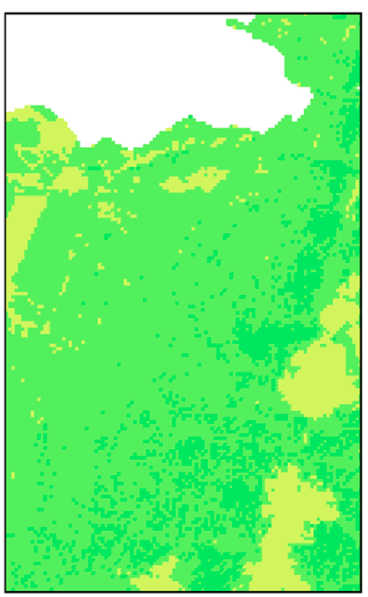

(C)

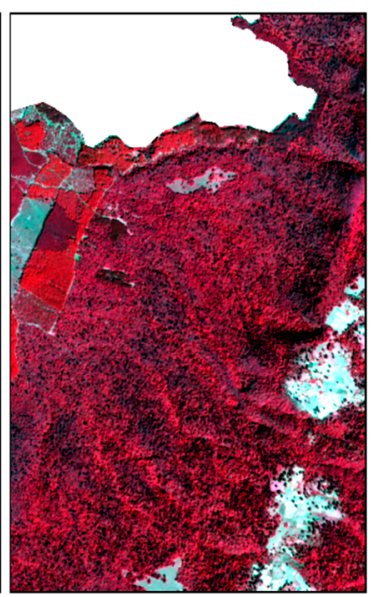

(D)

\begin{tabular}{|c|c|c|c|c|c|}
\hline Estimator data source & Lower limit of $95 \%$ CI & Upper limit of $95 \% \mathrm{CI}$ & & & $\operatorname{AGB}\left(\mathrm{Mg} \mathrm{ha}^{-1}\right)$ \\
\hline (A) & 159.60 & 209.10 & & & $-<100$ \\
\hline (B) & 161.76 & 206.95 & & & $100-$ \\
\hline (C) & 159.35 & 209.36 & & & $>600$ \\
\hline Field-based & 155.15 & 213.76 & 2 & $?$ & $4 \mathrm{~km}$ \\
\hline
\end{tabular}

Figure 4. Visual representation of a portion of the predicted AGB using the selected models of (A) L8, (B) S2, (C) PS and (D) false-color composite (NIR-R-G in the R-G-B channels) of the S2 image of the study area acquired on 14 January 2019. The $95 \%$ CI for the mean AGB estimates of the respective model predictions for the population are shown in the table. 


\section{Discussion}

\subsection{Variable Exploration for Estimating AGB and Model Selection}

The observed moderate relationships of independent variables of the RS data with AGB demonstrated the potential of optical RS data for developing models to enhance AGB estimation. The observed negative correlation coefficients between the mean of SB reflectance and AGB agree with results of similar studies conducted in various forest types $[19,75,76]$. The negative correlation coefficients indicate the inverse relationship between reflectance values from the SBs and AGB. This relationship in the current study could be explained by a shadow effect within the complex forest stands where AGB is large [77,78]. The presence of scattered big trees in SPs with large AGB results in large shadows. Additionally, such an effect might be related to large canopy water content, which is directly linked to photosynthetic efficiency [79]. The reflectance of the SBs from uniform forest stands like young plantations is large but they have relatively small AGB.

The positive relationship of most of the SIs with AGB found in this study is in accordance with previous research findings $[19,34,76]$. Besides the mean of SIs, the standard deviation of some SIs had also remarkable potential to relate with AGB. Næsset et al. [16] got similar results in Tanzania. Reviewed literature indicated that application of some of the SIs like the GLI, ExGI and NDGI have been limited to assessing grass biomass and crop cover or yield estimation. However, the current study showed that they had great potential to predict AGB in this type of forest. Thus, an in-depth study is required to understand the potential of such SIs for AGB estimation in different forest types.

It was revealed from the correlation analysis that most of the predictor variables in each satellite data type were intercorrelated. Lu et al. [80] found a similar result for estimation of AGB in wheat using an unmanned aerial vehicle. Among the different SBs the visible and SWIR bands, which are affected by atmospheric interference and shadow, were more strongly intercorrelated [78]. Besides, the SIs and texture variables were derived from these interrelated SBs. Therefore, the observed intercorrelation among the independent variables was likely to happen. This suggests the importance of a careful screening of RS variables for AGB modelling.

Furthermore, inter-resolution comparison of SBs showed that the limited spectral properties of the PS images might have restricted their potential to characterize AGB. For example, AGB correlated similarly with the G SB from each of the three image sources regardless of the differences in spatial resolution. The study results showed that the same SB across the resolution gradient characterized AGB similarly, indicating only a minor impact of pixel resolution on the quality of the AGB models if only SBs are related to AGB (Table 4). We observed that the S2 data contain a range of SBs that were more sensitive to AGB than the PS data, which have a higher spatial resolution.

Based on the relationship of the independent variables with AGB, we identified useful variables and models for each satellite data source. For example, exploration of the L8 data revealed that the NDMI showed a stronger correlation with AGB than other SI variables including the NDVI. This might be due to the improvements in the NDMI to detect leaf water content at the canopy level [7]. Previous research indicated that NDMI is useful for predicting forest attributes, including biomass [35,81]. The NDVI, which is the most popular SI for AGB modelling mostly in the temperate and boreal forests, was not a good predictor of AGB in the current study. Sader et al. [32] got similar results indicating unsuitability of NDVI for estimating AGB in tropical dense forests.

However, for the L8 data, AGB had a stronger correlation with SBs than the SIs mentioned above. Even among the SBs, AGB strongly correlated with the mean of SWIR1. The significance of the SWIR1 variable for AGB modelling was according to the results of other studies [23]. A study of biomass estimation using RS data in India indicated that biomass models using the SWIR bands were more reliable than those using short-wavelength SBs like the visible bands, which are more sensitive to atmospheric effects [82,83]. For green vegetation, reflectance in the SWIR spectral regions is controlled by the amount of water in the leaf biomass of the canopy. There is low diffuse of light at the SWIR wavelengths, and hence shadows are contrasted. The presence of thick layers of fragmented tree 
canopy and shadows in SPs with large AGB yielded low reflectance in the SBs, including the SWIR1 SB as indicated with the negative coefficient in the selected model.

The S2 model used for AGB estimation was the two-variable model with the independent variables of the mean of SWIR1 and standard deviation of GLI. Inclusion of the standard deviation of the GLI variable in the S2 model indicates the ability to capture spatial variation in canopy structure in the forest as the GLI can identify green leaves and stems from the background soil surface [60]. This variable may reflect the level of disturbance, terrain variation or presence of very big scattered trees in the natural forest. This variable signifies the importance of using measures of variability derived from higher resolution images in AGB modelling. The mean of ExGI was also another variable from the S2 data sensitive to AGB variability.

Besides the SBs and SIs, texture variables of the PS images had considerable potential for AGB modelling. The standard deviation of B4ASM that was included in one of the PS models, indicating the importance of high-resolution images for AGB modelling. Image texture variables like the ASM, describe the spatial arrangement of pixels with varying intensities that resulted in different AGB. The texture variables were able to differentiate between heterogeneous and homogenous surfaces, which prevailed in the disturbed natural forest patches and young plantation forests, respectively. This might be the reason for the observed strong positive relationship of the standard deviation of B4ASM with AGB. Improvement in the model performance by including this texture variable was in line with the findings of other studies $[24,39,84]$. Nevertheless, the two-variable model containing the standard deviation of B4ASM was subject to overfitting as compared to the reduced model with the mean of the $G$ reflectance variable (Table 5).

\subsection{Model Characteristics and Their Contribution to Enhance AGB Estimation}

Generally, the selected L8 and PS models explained some proportion of the variability in the ground reference AGB that was better than the results from [16] although the nature of the current forest and terrain configuration was complex. The calibration RMSEs of the L8 and PS models were $71.06 \%$ and $71.79 \%$ of the mean of the ground reference AGB, respectively. This was comparable with the results of other studies conducted even in intermediate vegetation cover conditions where it is easier to get a stronger relationship between image data and AGB [70]. The REf of the AGB estimates based on the selected L8 and PS models were 1.40 and 1.37, respectively. That means the selected L8 and PS models could reduce sample sizes to $71 \%$ and $73 \%$, respectively, of the field sample size to get the same precision with the FBSS estimates. These amounts (or proportions) of the variability in the field estimates remained unexplained when the model-assisted estimation was applied. Consequently, there was a similarity in improving the mean AGB estimates based on the L8 and PS models. The REf when using the L8 model in this study was slightly larger than the findings by Næsset et al. [16] for Miombo woodlands in Tanzania using the global Landsat products.

The selected S2 model contributed more strongly to improve the precision of the AGB estimates than the L8 and PS models. This improvement in estimation efficiency contributes to reducing the number of field SPs required to attain the same precision, to approximately $59 \%$ of the sample size required for a pure FBSS estimate. The REf when using the S2 model was smaller than that of the RapidEye images used for AGB estimation in the Miombo woodlands in Tanzania [16]. This might be attributed to the heterogeneity of the forest in the current study or the interaction effect of forest types and spatial resolution of the images. Besides, [16] stated that the small study area covered in their study might have resulted in overly optimistic results because the RS data were very homogenous since they came from only a single scene. On the other hand, the results of the current study were similar to the findings by Navarro et al. [21] who studied AGB of mangrove plantations using S2 images in Senegal. Thus, the findings of the current study are reasonable given the heterogeneity of the terrain and forest conditions, which influence the relationship of image data and AGB [83].

Although there might be some variations between the models in this regard, they were able to predict only to a limited range of the ground reference AGB. This shows a saturation problem for 
which canopy shadow is mainly responsible in the SPs with large AGB. Similar studies in primary and successional forests in Brazil indicated that shadows were among the main factors resulting in data saturation, particularly in natural forests with large AGB [77]. Modelling of tree heights might also contribute to the low/moderate estimation efficiencies in these models. There is uncertainty inherent in the field measurements of AGB, which could be caused by the AGB estimation procedure (e.g., errors in measurement and in the allometric models). The error in the height-DBH models could increase the uncertainties and limit performance of the models. Therefore, future efforts should focus on synchronizing other auxiliary variables like canopy density and canopy height from airborne laser scanning data with the identified variables to improve the model performances.

During the fieldwork, understory vegetation was observed in SPs (see Figure 5). The inflated predictions at SPs with small AGB might be attributed to this phenomenon. The field inventory was limited to trees with $\mathrm{DBH} \geq 5 \mathrm{~cm}$ and did not account for the understory vegetation. Dense understory vegetation composed of saplings, shrubs, lianas and herbaceous species covered most of these SPs and challenged our movement during the fieldwork. The biomass in the understory vegetation, which was not accounted for in the ground reference AGB, could have had a major influence on the SB reflectance values and hence in all the RS variables. This might partly explain the moderate improvement in the precision of the model-assisted estimates of AGB compared to the pure field-based estimate. As shown in Table 6, the PS model-assisted estimates had negative MD indicating the greater effect of the inflated predictions at SPs with small AGB than the reduced predictions at the SPs with large AGB. Thus, the effect of understory vegetation on the relationship between image-derived variables and AGB was more obvious when using the high-resolution PS images. A greater compliance of the RS data with AGB would happen for homogeneous forests in which the understory vegetation cover is minimal and the forest canopy cover is uniform. Therefore, further studies are needed in pure plantation forests to attain an optimum efficiency of RS data for AGB estimation beyond the ones we got in this study.

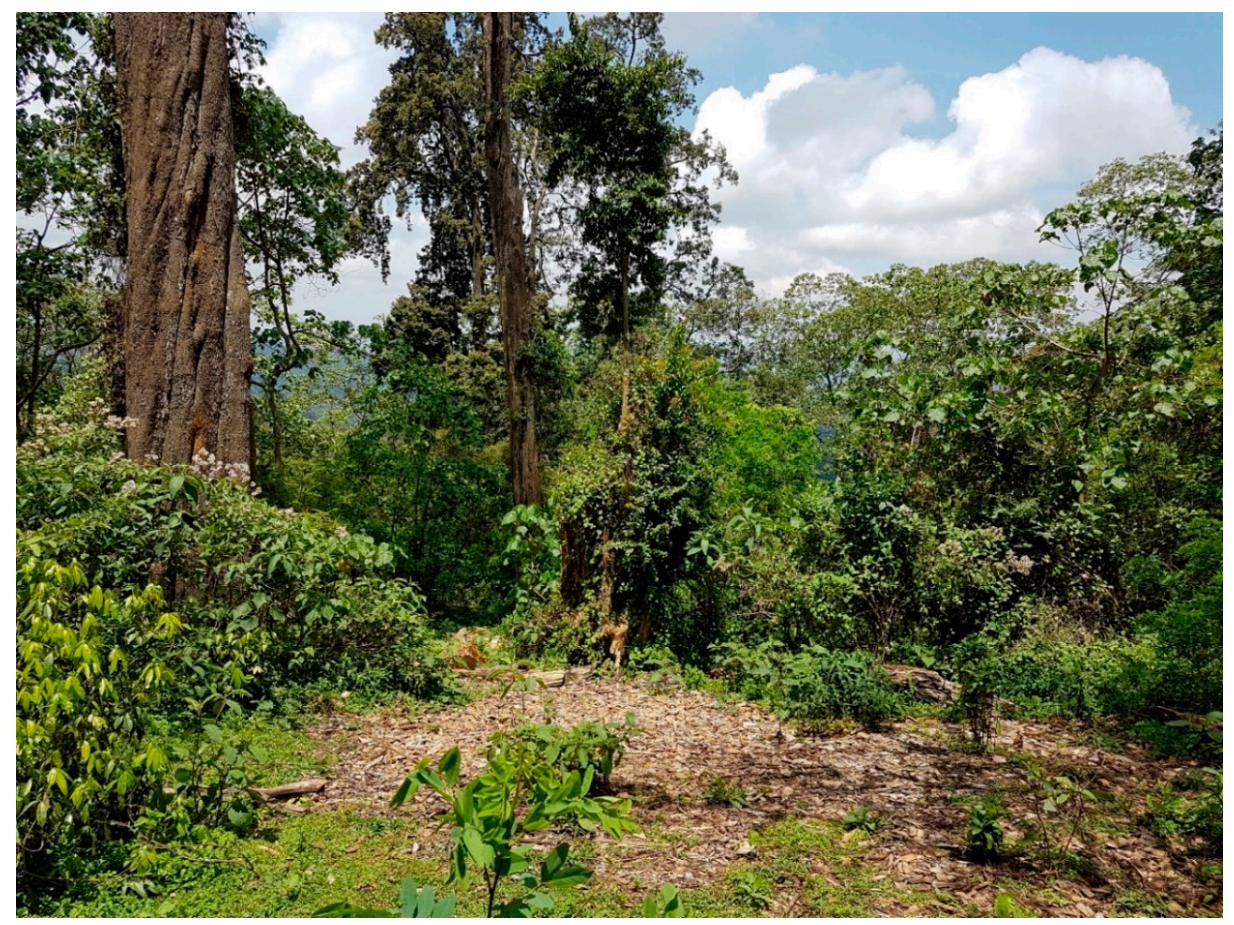

Figure 5. Understory vegetation in a forest SP. The understory vegetation that was not measured during the forest inventory could have influenced the image values and thus their relationship with AGB.

Generally, the findings of the current study were encouraging. We identified relevant variables extracted from RS data for AGB estimation. The selected models of each satellite data source based on 
the identified variables provided reasonable improvements in AGB estimations, which were reinforced by other research findings. The freely available S2 data were particularly useful. The research results revealed that $\mathrm{S} 2$ images possess sensible spectral and spatial properties for AGB estimation. The results of this study will help to satisfy the existing demand for forest carbon stock assessment by the national REDD+ program in Ethiopia. Enhanced forest information using the freely available data sources like the S2 would help to improve sustainable forest management and encourage results-based payments for those who properly manage their forest resources according to established principles like the REDD+ schemes.

\section{Conclusions}

Optical RS images from L8, S2 and PS satellites were studied to identify relevant RS predictor variables that could be used to enhance AGB estimation in a dry Afromontane forest. Most of the SBs, some SIs and texture variables (listed in Table 4) were found to be promising variables for predicting AGB. Although some of them were not selected in the models used for assisting AGB estimation, we identified variables including the mean of GLI, ExGI and NDGI that were seldom used for AGB modelling but are highly correlated with AGB. We recommend a detailed investigation of the importance of these variables for AGB assessment in various forest conditions.

The simple models selected for each satellite data source enhanced AGB estimation. Of the variables used in the models, the SWIR1 SB, which lacks in the PS data, was a useful variable of the L8 and S2 images for AGB estimation in this forest type despite the huge differences in pixel resolution among the image types. The study suggested that the additional spectral information of L8 and S2 images was more determinant of AGB estimation than the small pixel size of the PS images.

The use of RS data for AGB estimation improved the precision of estimates. Thus, the remote sensing-assisted estimation techniques used in this study will complement the FBSS estimates of AGB by improving precision. The model-assisted estimation will reduce sample sizes to obtain a similar estimation efficiency with the field survey. However, the models used for AGB estimation in this study revealed saturation problem. Therefore, future studies should focus on refining these limitations using a synergy of different data sources to enhance the estimation efficiency of AGB models beyond the ones achieved in the current study.

The methods used in this study could be adopted to similar conditions in forests that have limited application of RS data. The potential predictor variables derived from optical satellite images for biomass estimation were identified from studies showing global experiences. Exploratory data analysis was used to identify relevant predictor variables for biomass estimation in the current study site. Choice of a model form that is important for biomass required understanding the characteristics of data types. The selected models for each image type predicted biomass with estimation efficiencies comparable with those obtained in other forest types. These methods contain a unique mix of techniques capable of using satellite images for biomass estimation in a data scarce forest type.

Author Contributions: H.T. proposed the research idea. H.T., Z.A., T.G., I.B., H.O.Ø., E.N. and Ø.B.D. designed the field sampling protocols. H.T. carried out the RS data processing and analysis. H.T. and Z.A. implemented the field data collection, did data analysis and wrote the manuscript. T.G., H.O.Ø., I.B., E.N. and Ø.B.D. supervised the data analysis. All authors have read and agreed to the published version of the manuscript.

Funding: 'National MRV Capacity Building towards Climate Resilient Development in Ethiopia' Project: ETH 14/0002.

Acknowledgments: The Norwegian government funded this study through the "National MRV Capacity Building towards Climate Resilient Development in Ethiopia" program for which we have a profound gratitude. We appreciate the support we got from Wondo Genet College of Forestry and Natural Resources-Hawassa University, Ethiopia and Norwegian University of Life Sciences, Norway. We are grateful for the support we got from the Planet Company for offering free access to its high-resolution satellite images. We would like to thank Marie-Claude Jutras-Perreault for processing the GNSS data. We are indebted to both headquarter and Arsi branch offices of the Oromia forest and wildlife enterprise, local government and all members of the field crew for their cooperation during the data collection.

Conflicts of Interest: The authors declare no conflict of interest. 


\section{References}

1. Bonan, G.B. Forests and climate change: Forcings, feedbacks, and the climate benefits of forests. Science 2008, 320, 1444-1449. [CrossRef] [PubMed]

2. Anderson, J.W. The Kyoto Protocol on Climate Change; Resources for the Future: Washington, DC, USA, 1998; pp. 1-21. Available online: https://media.rff.org/documents/RFF-RPT-kyotoprot.pdf (accessed on 17 September 2019).

3. UNFCCC. Decisions adopted by the Conference of the Parties. In Proceedings of the Conference of the Parties on Its Fifteenth Session, Copenhagen, Denmark, 7-19 December 2009; pp. 1-43. Available online: https://unfccc.int/resource/docs/2009/cop15/eng/11a01.pdf (accessed on 17 September 2019).

4. UNFCCC. Adoption of the Paris Agreement Proposal by the President. In Proceedings of the Paris Climate Change Conference-COP 21, Paris, France, 21 December 2015; pp. 1-31. Available online: https://unfccc.int/ resource/docs/2015/cop21/eng/109.pdf (accessed on 16 September 2019).

5. Gerhardt, K.; Hytteborn, H. Natural dynamics and regeneration methods in tropical dry forests-An introduction. J. Veg. Sci. 1992, 3, 361-364. [CrossRef]

6. Price, M.; Gratzer, G.; Alemayehu Duguma, L.; Kohler, T.; Maselli, D. Mountain Forests in a Changing World: Realizing Values, Addressing Challenges; Food and Agriculture Organization of the United Nations (FAO) and Centre of Development and Environment (CDE): Rome, Italy, 2011; ISBN 978-92-5-107076-5. Available online: http://www.fao.org/3/a-i2481e.pdf (accessed on 29 November 2019).

7. Solomon, N.; Segnon, A.C.; Birhane, E. Ecosystem Service Values Changes in Response to Land-Use/Land-Cover Dynamics in Dry Afromontane Forest in Northern Ethiopia. Int. J. Environ. Res. Public Health 2019, 16, 4653. [CrossRef] [PubMed]

8. Lemenih, M.; Bongers, F. Dry Forests of Ethiopia and Their Silviculture. In Silviculture in the Tropics; Günter, S., Weber, M., Stimm, B., Mosandl, R., Eds.; Springer: Berlin/Heidelberg, Germany, 2011; Volume 8, pp. 261-272. [CrossRef]

9. Nguon, P.; Kulakowski, D. Natural forest disturbances and the design of REDD+ initiatives. Environ. Sci. Policy 2013, 33, 332-345. [CrossRef]

10. Kebede, B.; Soromessa, T. Allometric equations for aboveground biomass estimation of Olea europaea L. subsp.cuspidatain Mana Angetu Forest. Ecosyst. Health Sustain. 2018, 4, 1-12. [CrossRef]

11. Duncanson, L.; Rourke, O.; Dubayah, R. Small Sample Sizes Yield Biased Allometric Equations in Temperate Forests. Sci. Rep. 2015, 5, 1-13. [CrossRef]

12. Watson, C.; Mourato, S.; Milner-Gulland, E.J. Uncertain Emission Reductions from Forest Conservation: REDD in the Bale Mountains, Ethiopia. Ecol. Soc. 2013, 18,1-16. [CrossRef]

13. Hashim, M.; Pour, A.B.; Chong, K.W. Tropical forest degradation monitoring using ETM+ and MODIS remote sensing data in the Peninsular Malaysia. IOP Conf. Ser. Earth Environ. Sci. 2014, 18, 1-6. [CrossRef]

14. Ingole, N.A.; Ram, R.N.; Ranjan, R.; Shankhwar, A.K. Advance application of geospatial technology for fisheries perspective in Tarai region of Himalayan state of Uttarakhand. Sustain. Water Resour. Manag. 2015, 1, 181-187. [CrossRef]

15. Koch, B. Remote Sensing supporting national forest inventories NFA. In FAO Knowledge Reference for National Forest Assessments; FAO: Rome, Italy, 2015; pp. 77-92. Available online: http://www.fao.org/3/a-i4822e.pdf (accessed on 16 December 2019).

16. Næsset, E.; Ørka, H.O.; Solberg, S.; Bollandsås, O.M.; Hansen, E.H.; Mauya, E.; Zahabu, E.; Malimbwi, R.; Chamuya, N.; Olsson, H.; et al. Mapping and estimating forest area and aboveground biomass in miombo woodlands in Tanzania using data from airborne laser scanning, TanDEM-X, RapidEye, and global forest maps: A comparison of estimated precision. Remote Sens. Environ. 2016, 175, 282-300. [CrossRef]

17. Malenovský, Z.; Rott, H.; Cihlar, J.; Schaepman, M.E.; García-Santos, G.; Fernandes, R.; Berger, M. Sentinels for science: Potential of Sentinel-1, -2, and -3 missions for scientific observations of ocean, cryosphere, and land. Remote Sens. Environ. 2012, 120, 91-101. [CrossRef]

18. Woodcock, C.E.; Allen, R.; Anderson, M.; Belward, A.; Bindschadler, R.; Cohen, W.; Gao, F.; Goward, S.N.; Helder, D.; Helmer, E.; et al. Free access to Landsat imagery. Sci. Lett. 2008, 320, 1011-1012. [CrossRef] [PubMed]

19. Gizachew, B.; Solberg, S.; Naesset, E.; Gobakken, T.; Bollandsas, O.M.; Breidenbach, J.; Zahabu, E.; Mauya, E.W. Mapping and estimating the total living biomass and carbon in low-biomass woodlands using Landsat 8 CDR data. Carbon Balance Manag. 2016, 11, 1-14. [CrossRef] [PubMed] 
20. Li, C.; Li, Y.; Li, M. Improving Forest Aboveground Biomass (AGB) Estimation by Incorporating Crown Density and Using Landsat 8 OLI Images of a Subtropical Forest in Western Hunan in Central China. Forests 2019, 10, 104. [CrossRef]

21. Navarro, J.A.; Algeet, N.; Fernández-Landa, A.; Esteban, J.; Rodríguez-Noriega, P.; Guillén-Climent, M.L. Integration of UAV, Sentinel-1, and Sentinel-2 Data for Mangrove Plantation Aboveground Biomass Monitoring in Senegal. Remote Sens. 2019, 11, 77. [CrossRef]

22. Qiu, A.; Yang, Y.; Wang, D.; Xu, S.; Wang, X. Exploring parameter selection for carbon monitoring based on Landsat-8 imagery of the aboveground forest biomass on Mount Tai. Eur. J. Remote Sens. 2019, 52, 1-12. [CrossRef]

23. Risdiyanto, I.; Fakhrul, M. Examination of Multi-Spectral Radiance of the Landsat 8 Satellite Data for Estimating Biomass Carbon Stock at Wetland Ecosystem. Preprints 2017, 1-14. [CrossRef]

24. Sousa, A.M.O.; Gonçalves, A.C.; da Silva, J.R.M. Above-Ground Biomass Estimation with High Spatial Resolution Satellite Images. In Biomass Volume Estimation and Valorization for Energy; Tumuluru, J.S., Ed.; InTech: Rijeka, Croatia, 2017; Volume 2017, pp. 47-70. [CrossRef]

25. Sousa, A.M.O.; Gonçalves, A.C.; Mesquita, P.; Marques da Silva, J.R. Biomass estimation with high resolution satellite images: A case study of Quercus rotundifolia. ISPRS J. Photogramm. Remote Sens. 2015, 101, 69-79. [CrossRef]

26. Baloloy, A.B.; Blanco, A.C.; Candido, C.G.; Argamosa, R.J.L.; Dumalag, J.B.L.C.; Dimapilis, L.L.C.; Paringit, E.C. Estimation of Mangrove Forest Aboveground Biomass Using Multispectral Bands, Vegetation Indices and Biophysical Variables Derived from Optical Satellite Imageries: Rapideye, Planetscope and Sentinel-2. ISPRS Ann. Photogramm. Remote Sens. Spat. Inf. Sci. 2018, IV-3, 29-36. [CrossRef]

27. Lu, D. Aboveground biomass estimation using Landsat TM data in the Brazilian Amazon. Int. J. Remote Sens. 2007, 26, 2509-2525. [CrossRef]

28. López-Serrano, P.M.; López-Sánchez, C.A.; Álvarez-González, J.G.; García-Gutiérrez, J. A Comparison of Machine Learning Techniques Applied to Landsat-5 TM Spectral Data for Biomass Estimation. Can. J. Remote Sens. 2016, 42, 690-705. [CrossRef]

29. Günlü, A.; Ercanli, I.; Başkent, E.Z.; Çakır, G. Estimating aboveground biomass using Landsat TM imagery: A case study of Anatolian Crimean pine forests in Turkey. Ann. For. Res. 2014, 57, 289-298. [CrossRef]

30. Das, S.; Singh, T.P. Correlation analysis between biomass and spectral vegetation indices of forest ecosystem. Int. J. Eng. Res. Technol. 2012,1,1-13.

31. Ringrose, S.; Matheson, W.; Matlala, C.J.S.S.; O'Neill, T.; Werner, P.A. Vegetation spectral reflectance along a north-south vegetation gradient in northern Australia. J. Biogeogr. 1994, 21, 33-47. [CrossRef]

32. Sader, S.A.; Waide, R.B.; Lawrence, W.T.; Joyce, A.T. Tropical forest biomass and successional age class relationships to a vegetation index derived from Landsat TM data. Remote Sens. Environ. 1989, 28, 143-156. [CrossRef]

33. Viña, A.; Gitelson, A.A.; Nguy-Robertson, A.L.; Peng, Y. Comparison of different vegetation indices for the remote assessment of green leaf area index of crops. Remote Sens. Environ. 2011, 115, 3468-3478. [CrossRef]

34. Macedo, F.L.; Sousa, A.M.O.; Gonçalves, A.C.; Marques da Silva, J.R.; Mesquita, P.A.; Rodrigues, R.A.F. Above-ground biomass estimation for Quercus rotundifolia using vegetation indices derived from high spatial resolution satellite images. Eur. J. Remote Sens. 2018, 51, 932-944. [CrossRef]

35. Imran, A.B.; Khan, K.; Ali, N.; Ahmad, N.; Ali, A.; Shah, K. Narrow band based and broadband derived vegetation indices using Sentinel-2 Imagery to estimate vegetation biomass. Glob. J. Environ. Sci. Manag. 2020, 6, 97-108. [CrossRef]

36. Motohka, T.; Nasahara, K.N.; Oguma, H.; Tsuchida, S. Applicability of Green-Red Vegetation Index for Remote Sensing of Vegetation Phenology. Remote Sens. 2010, 2, 2369. [CrossRef]

37. Larrinaga, A.R.; Brotons, L. Greenness Indices from a Low-Cost UAV Imagery as Tools for Monitoring Post-Fire Forest Recovery. Drones 2019, 3, 6. [CrossRef]

38. Sonnentag, O.; Hufkens, K.; Teshera-Sterne, C.; Young, A.M.; Friedl, M.; Braswell, B.H.; Milliman, T.; O'Keefe, J.; Richardson, A.D. Digital repeat photography for phenological research in forest ecosystems. Agric. For. Meteorol. 2012, 152, 159-177. [CrossRef]

39. Kelsey, K.; Neff, J. Estimates of Aboveground Biomass from Texture Analysis of Landsat Imagery. Remote Sens. 2014, 6, 6407-6422. [CrossRef] 
40. Otukei, J.R.; Emanuel, M. Estimation and mapping of above ground biomass and carbon of Bwindi impenetrable National Park using ALOS PALSAR data. S. Afr. J. Geomat. 2015, 4, 1-13. [CrossRef]

41. Duriaux, J.Y.; Baudron, F. Understanding people and forest interrelations along an intensification gradient in Arsi-Negele, Ethiopia. In Agrarian Change in Tropical Landscapes; Deakin, L., Kshatriya, M., Sunderland, T., Eds.; Center for International Forestry Research (CIFOR): Bogor, Indonesia, 2016; pp. 14-53.

42. Asrat, Z.; Eid, T.; Gobakken, T.; Negash, M. Aboveground tree biomass prediction options for the Dry Afromontane forests in south-central Ethiopia. For. Ecol. Manag. 2020, 473, 1-14. [CrossRef]

43. Topcon Positioning Systems Inc. Available online: https://www.topconpositioning.com/gb/gnss-networksolutions (accessed on 16 September 2019).

44. Kouba, J. A Guide to Using International GNSS Service (IGS) Products. 2009, p. 34. Available online: https://www.researchgate.net/profile/Jan_Kouba/publication/228663800_A_guide_to_using_International_ GNSS_Service_IGS_products/links/54fcc30c0cf270426d102cd3.pdf (accessed on 18 May 2020).

45. MAGNET Tools 1.0; Topcon Positioning Systems Inc.: Livermore, CA, USA, 2012; Available online: https://www. tigersupplies.com/files/bcf31975-d2e6-44c2-ba66-7bad3a95cdb3HLP_MAGNET_Office_Tools_v1_0_EN.pdf (accessed on 21 September 2019).

46. Haglöf Company Group. Available online: http://www.haglofsweden.com/index.php/en/products/instruments/ height/541-the-vertex-laser-geo-all-you-need-in-a-rangefinder-hypsometer (accessed on 12 November 2019).

47. Sullivan, M.J.P.; Lewis, S.L.; Hubau, W.; Qie, L.; Baker, T.R.; Banin, L.F.; Chave, J.; Cuni-Sanchez, A.; Feldpausch, T.R.; Lopez-Gonzalez, G.; et al. Field methods for sampling tree height for tropical forest biomass estimation. Methods Ecol. Evol. 2018, 9, 1179-1189. [CrossRef] [PubMed]

48. Asrat, Z.; Eid, T.; Gobakken, T.; Negash, M. Modeling and quantifying tree biometric properties of Dry Afromontane forests of South-central Ethiopia. Trees 2020. under review. [CrossRef]

49. Berhe, L.; Assefa, G.; Teklay, T. Models for estimation of carbon sequestered by Cupressus lusitanica plantation stands at Wondo Genet, Ethiopia. South For. 2013, 75, 113-122. [CrossRef]

50. Ounban, W.; Puangchit, L.; Diloksumpun, S. Development of general biomass allometric equations for Tectona grandis Linn. f. and Eucalyptus camaldulensis Dehnh. plantations in Thailand. Agric. Nat. Resour. 2016, 50, 48-53. [CrossRef]

51. Owate, O.A.; Mware, M.J.; Kinyanjui, M.J. Allometric Equations for Estimating Silk Oak (Grevillea robusta) Biomass in Agricultural Landscapes of Maragua Subcounty, Kenya. Int. J. For. Res. 2018, 1-14. [CrossRef]

52. USGS. USGS Earth Explorer. Available online: https://earthexplorer.usgs.gov/ (accessed on 23 August 2019).

53. Planet. Planet Explorer. Available online: https://www.planet.com/explorer/ (accessed on 3 September 2019).

54. QGIS Development Team. QGIS-A Free and Open Source Geographic Information System. Available online: https://www.qgis.org/en/site/ (accessed on 23 November 2019).

55. Huete, A.; Justice, C.; Van Leeuwen, W. MODIS Vegetation Index (MOD13). Algorithm Theoretical Basis Document. p. 129. 1999. Available online: https://modis.gsfc.nasa.gov/data/atbd/atbd_mod13.pdf (accessed on 16 October 2019).

56. Rouse, J.W.; Hass, R.H.; Schell, J.A.; Deering, D.W.; Harlan, J.C. Monitoring the Vernal Advancement and Netrogradation (Greenwave Effect) of Natural Vegetation; Texas A\&M University: College Station, TX, USA, 1974; p. 390.

57. Jordan, C.F. Derivation of leaf-area index from quality of light on the forest floor. Ecology 1969, 5, $663-666$. [CrossRef]

58. Adamsen, F.J.; Pinter, P.J.; Barnes, E.M.; LaMorte, R.L.; Wall, G.W.; Leavitt, S.W.; Kimball, B.A. Measuring wheat senescence with a digital camera. Crop Sci. 1999, 39, 719-724. [CrossRef]

59. Richardson, A.J.; Wiegand, C.L. Distinguishing vegetation from soil background information. Photogramm. Eng. Remote Sens. 1977, 43, 1541-1552.

60. Louhaichi, M.; Borman, M.M.; Johnson, D.E. Spatially Located Platform and Aerial Photography for Documentation of Grazing Impacts on Wheat. Geocarto Int. 2001, 16, 65-70. [CrossRef]

61. Liu, H.Q.; Huete, A. A feedback based modification of the NDVI to minimize canopy background and atmospheric noise. IEEE Trans. Geosci. Remote Sens. 1995, 33, 457-465. [CrossRef]

62. Huete, A.R. A soil-adjusted vegetation index (SAVI). Remote Sens. Environ. 1988, 25, 295-309. [CrossRef]

63. Qi, J.; Kerr, Y.; Chehbouni, A. External factor consideration in vegetation index development. In Proceedings of the 6th International Symposium on Physical Measurements and Signatures in Remote Sensing, Val d'lsère, France, 17-21 January 1994; pp. 723-730. 
64. Gao, B.C. NDWI-A normalized difference water index for remote sensing of vegetation liquid water from space. Remote Sens. Environ. 1996, 58, 257-266. [CrossRef]

65. Kaufman, Y.J.; Tanre, D. Atmospherically resistant vegetation index (ARVI) for EOS-MODIS. IEEE Trans. Geosci. Remote Sens. 1992, 30, 261-270. [CrossRef]

66. Rajah, P.; Odindi, J.; Mutanga, O.; Kiala, Z. The utility of Sentinel-2 Vegetation Indices (VIs) and Sentinel-1 Synthetic Aperture Radar (SAR) for invasive alien species detection and mapping. Nat. Conserv. 2019, 35, 41-61. [CrossRef]

67. Torino, M.S.; Ortiz, B.V.; Fulton, J.P.; Balkcom, K.S.; Wood, C.W. Evaluation of Vegetation Indices for Early Assessment of Corn Status and Yield Potential in the Southeastern United States. Agron. J. 2014, 106, 1389-1401. [CrossRef]

68. Gitelson, A.; Merzlyak, M.N. Quantitative estimation of chlorophyll-a using reflectance spectra: Experiments with autumn chestnut and maple leaves. J. Photochem. Photobiol. B Biol. 1994, 22, 247-252. [CrossRef]

69. ESA. SNAP Version 7.0.0. Available online: http://step.esa.int/main/download/snap-download/ (accessed on 28 August 2019).

70. Magnussen, S.; Næsset, E.; Gobakken, T. An application niche for finite mixture models in forest resource surveys. Can. J. For. Res. 2019, 49, 1453-1462. [CrossRef]

71. Särndal, C.E.; Swensson, B.; Wretman, J. Model Assisted Survey Sampling; Springer: New York, NY, USA, 1992; p. 694.

72. Magnussen, S.; Næsset, E.; Kändler, G.; Adler, P.; Renaud, J.P.; Gobakken, T. A functional regression model for inventories supported by aerial laser scanner data or photogrammetric point clouds. Remote Sens. Environ. 2016, 184, 496-505. [CrossRef]

73. Salinas-Melgoza, M.A.; Skutsch, M.; Lovett, J.C. Predicting aboveground forest biomass with topographic variables in human-impacted tropical dry forest landscapes. Ecosphere 2018, 9, 1-20. [CrossRef]

74. Schober, P.; Boer, C.; Schwarte, L.A. Correlation Coefficients: Appropriate Use and Interpretation. Anesth. Analg. 2018, 126, 1763-1768. [CrossRef] [PubMed]

75. Bao, N.; Li, W.; Gu, X.; Liu, Y. Biomass Estimation for Semiarid Vegetation and Mine Rehabilitation Using Worldview-3 and Sentinel-1 SAR Imagery. Remote Sens. 2019, 11, 2855. [CrossRef]

76. Lorenzen, B.; Jensen, A. Reflectance of blue, green, red and near infrared radiation from wetland vegetation used in a model discriminating live and dead above ground biomass. New Phytol. 1988, 108, 345-355. [CrossRef]

77. Lu, D.; Batistella, M.; Moran, E. Satellite estimation of aboveground biomass and impacts of forest stand structure. Photogramm. Eng. Remote Sens. 2005, 71,967-974. [CrossRef]

78. Wang, Q.; Pang, Y.; Li, Z.; Sun, G.; Chen, E.; Ni-Meister, W. The Potential of Forest Biomass Inversion Based on Vegetation Indices Using Multi-Angle CHRIS/PROBA Data. Remote Sens. 2016, 8, 891. [CrossRef]

79. Prasad, B.; Babar, M.A.; Carver, B.F.; Raun, W.R.; Klatt, A.R. Association of biomass production and canopy spectral reflectance indices in winter wheat. Can. J. Plant. Sci. 2009, 89, 485-496. [CrossRef]

80. Lu, N.; Zhou, J.; Han, Z.; Li, D.; Cao, Q.; Yao, X.; Tian, Y.; Zhu, Y.; Cao, W.; Cheng, T. Improved estimation of aboveground biomass in wheat from RGB imagery and point cloud data acquired with a low-cost unmanned aerial vehicle system. Plant Methods 2019, 15, 1-16. [CrossRef]

81. Uyeda, K.A.; Stow, D.A.; Roberts, D.A.; Riggan, P.J. Combining ground-based measurements and MODIS-based spectral vegetation indices to track biomass accumulation in post-fire chaparral. Int. J. Remote Sens. 2016, 38, 728-741. [CrossRef]

82. Horler, D.N.H.; Ahern, F.J. Forestry information content of Thematic Mapper data. Int. J. Remote Sens. 1986, 7, 405-428. [CrossRef]

83. Roy, P.S.; Ravan, S.A. Biomass estimation using satellite remote sensing data-an investigation on possible approaches for natural forest. J. Biosci. 1996, 21, 535-561. [CrossRef]

84. Nichol, J.E.; Sarker, M.L.R. Improved Biomass Estimation Using the Texture Parameters of Two High-Resolution Optical Sensors. IEEE Trans. Geosci. Remote Sens. 2011, 49, 930-948. [CrossRef]

(C) 2020 by the authors. Licensee MDPI, Basel, Switzerland. This article is an open access article distributed under the terms and conditions of the Creative Commons Attribution (CC BY) license (http://creativecommons.org/licenses/by/4.0/). 